Article

\title{
Comparative Interrelationship of the Structural, Nonlinear-Optical and Other Acentric Properties for Oxide, Borate and Carbonate Crystals
}

\author{
Boris I. Kidyarov
}

A.V. Rzhanov Institute of Semiconductor Physics Siberian Branch of the Russian Academy of Science, Novosibirsk 630090, Russia; kidyarov@isp.nsc.ru

Academic Editors: Ning Ye and Rukang Li

Received: 3 February 2017; Accepted: 28 March 2017; Published: 12 April 2017

\begin{abstract}
The structure and the maximal nonlinear optical (NLO) susceptibility $\chi^{(2)}$ are tabulated for more 700 acentric binary oxides, 220 crystals of simple, binary and complex borates and for the same set of 110 carbonates, tartrates, formates, oxalates, acetates and fluoride-carbonates used in ultraviolet and deep ultraviolet optoelectronics. According to the chemical formula, the structural symbols of these crystals have been plotted on the plane of two minimal oxide bond lengths (OBL). It is shown that acentric crystals are positioned on such plane inside the vertical, horizontal and slope intersected ellipses of "acentricity". The oxide and borate crystals with moderate NLO susceptibility are found in the central parts of these ellipses intersection and, with low susceptibility, on top, at the bottom and border of the ellipses rosette. The nonpolar fluoride-carbonate crystals with high NLO susceptibility are found in the curve-side rhombic parts of the slope ellipse of "acentricity".

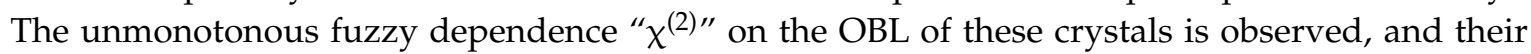
clear-cut taxonomy on compounds with $\pi$ - or $\sigma$-oxide bonds is also established. It is shown that the correlations of $\chi^{(2)}$ with other acentric properties are nonlinear for the whole set of the oxide crystals having their clear maximum at a certain value of the piezoelectric or electro-optic coefficient. The correlation "hardness-thermoconductivity-fusibility" is plotted for oxide crystals, part of which is used at the creation of self-frequency-doubling solid state lasers.
\end{abstract}

Keywords: structure; property; bond length; relationship; oxide; borate; carbonate crystals

\section{Introduction}

Modern fundamental material science is the main basis for the search and growth of new perspective crystals used at the creation of various solid state dielectric devices, particularly, for laser physics, acoustoelectronics or nonlinear optics (NLO) [1-6]. The noncentrosymmetric (NCS) crystals can only be useful for the last aims $[2,5,6]$. These crystals have simultaneously NLO, piezoelectric (PE), and electro-optic (EO) properties. But a set of centrosymmertic (CS) and NCS hardness crystals are more preferable for the creation of solid state lasers [3-5]. The number of NCS crystals with a suitable set of properties is restricted because part of acentric crystals, among all crystalline structures, makes up roughly $\sim 16 \%$, but part of crystals with desirable properties is less than $2 \%[7,8]$. The set of oxide compounds is the main part of natural minerals, and they are often useful in optoelectronics [2-6,9]. As the number of simple and binary oxide crystals is also restricted, then the ternary and multicomponent NCS oxide crystals are now the main source for the search of new promising NLO materials [10,11]. Over 137 years ago, a strong piezoelectric and ferroelectric crystal, the Rochelle salt, $\mathrm{NaKC}_{4} \mathrm{H}_{4} \mathrm{O}_{6} \cdot 4 \mathrm{H}_{2} \mathrm{O}_{\text {, }}$ $\mathrm{O} O \mathrm{O}$ then pyroelectric mineral, tourmaline $(\mathrm{Na}, \mathrm{Ca})(\mathrm{Mg}, \mathrm{Al})_{6}\left[\mathrm{~B}_{3} \mathrm{Al}_{3} \mathrm{Si}_{6}(\mathrm{O}, \mathrm{OH})_{30}\right.$, and a moderate piezoelectric $\alpha$-quartz [3,12] were found. Since 1921, the number of known ferroelectric crystals has been increasing continuously: $\mathrm{KH}_{2} \mathrm{PO}_{4}$ (1935), $\mathrm{BaTiO}_{3}$ (1945), $\mathrm{KNbO}_{3}$ (1951) and others [12,13]. In 1960 
the first solid state laser [4] was created, and then the second light harmonic generation was found in $\alpha$-quartz (NLO-effect) and in many NCS crystals [6].

Over 40 years ago, Chuangtian Chen proposed an anionic group theory for the NLO susceptibility, and the Chen's group succeeded in making a systematic elucidation of the structure-NLO-property relation in many principal types of NCS oxide crystals (nitrites, phosphates, iodates, niobates, titanates, tantalates), and that led to the development of a new borate series of ultraviolet (UV) materials [14-18]. Only in 2016 more than 100 contributions, in which many authors studied the synthesis and growth of new borate crystals, their structure and properties [19], were published. Besides, 20 years ago, new effective UV, NLO fluoride carbonate crystals, including $\mathrm{K}_{4} \mathrm{Ln}_{2}\left(\mathrm{CO}_{3}\right)_{3} \mathrm{~F}_{4}(\mathrm{Ln}=\mathrm{Pr}, \mathrm{Nd}, \mathrm{Sm}, \mathrm{Gd}$, Eu), then $\mathrm{CsPbCO}_{3} \mathrm{~F}$ and others [20-25], were found.

The excellent handbook on NLO-crystals was published in 2005 by David N. Nikogosyan [6]. The set of all oxide NLO-crystals was included in groups of basic, often-used, periodically poled, newly developed and perspective, self-frequency-doubling, rarely used and archive crystals. The set of NLO- and EO-oxide crystal properties is also presented and analyzed in books [26-28]. The set of all acentric and other properties of NCS-crystals were presented in the collective handbook [29]. For the last years, the properties and application of piezoelectric and ferroelectric crystals have been collected in some papers and books [3,30-36].

But the first collection of NCS crystals and their fundamental interrelationship "structureproperty" is presented in the review paper of 1998 [10]. Now further systematization of more two thousand acentric oxide crystals, with the aim of searching new promising piezoelectric (PE) and NLO oxide crystals for optoelectronics, is necessary. Namely, it is necessary to take into account a more thorough empirical interrelationship between NLO, PE, electro-optical (EO) properties, crystal point symmetry, and crystal microstructure $[11,37,38]$. Such studies were carried out earlier, particularly, in the series of our contributions [11,37-58]. It was shown that the oxide chemical bond lengths of mainly compound components can be a certain criterion for the formation of NCS crystals among many classes of chemical compounds: oxides, sulfides, selenides, tellurides, fluorides, bromides and chlorides. Besides the fuzzy character of quantitative interrelationship "chemical bond length-value of acentric property", the upper boundary of these empiric correlations is, certainly, of complete nonmonotonous character.

A repeated, more complete and extended analysis of this problem is required since there are continuous publications of new experimental data. Therefore, a general table of the relation "structure-set of acentric properties" for piezoelectric crystals and the key empiric interrelationship "oxide bond length-structure-nonlinear optical susceptibility", due to increasing lengths of anionic and cationic oxide bonds [11,37-45,49-51,53-58], are presented in this paper. The weak-known systematization of empiric interrelationship "property 1-property 2" between the NLO-, PE-, EO-properties was also revised and plotted for the set of oxide crystals [57]. It is only, in this paper that we mention the interrelationship between the hardness and melting temperature of oxide crystals, which is also very interesting at the creation of solid state lasers, abrasive and other crystals for optoelectronics [58]. Laser and NLO-elements are more stable if they are created from hard and refractory materials $[2,58]$.

\section{Triad of the Interrelationship "Composition-Structure-Property"}

\subsection{General View}

The understanding of qualitative and quantitative interrelationship between physico-chemical properties of crystal compounds, their compositions and structures is the key approach to searching and creating new crystalline materials $[10,11,59]$. For the establishment of quantitative correlations, it is desirable to find the useful microstructure parameter which is connected with the other triad characteristics. Such quaternion "composition-parameter-structure-property" is presented in Figure 1. The parameter, structure and property depend on a compound composition and the applied technology. 
It was shown earlier that the chemical bond length of the main compound component, which is dependent on the cationic and anionic radii $[11,37-58,60,61]$, is the more useful informative parameter for the acentric crystal systematization.

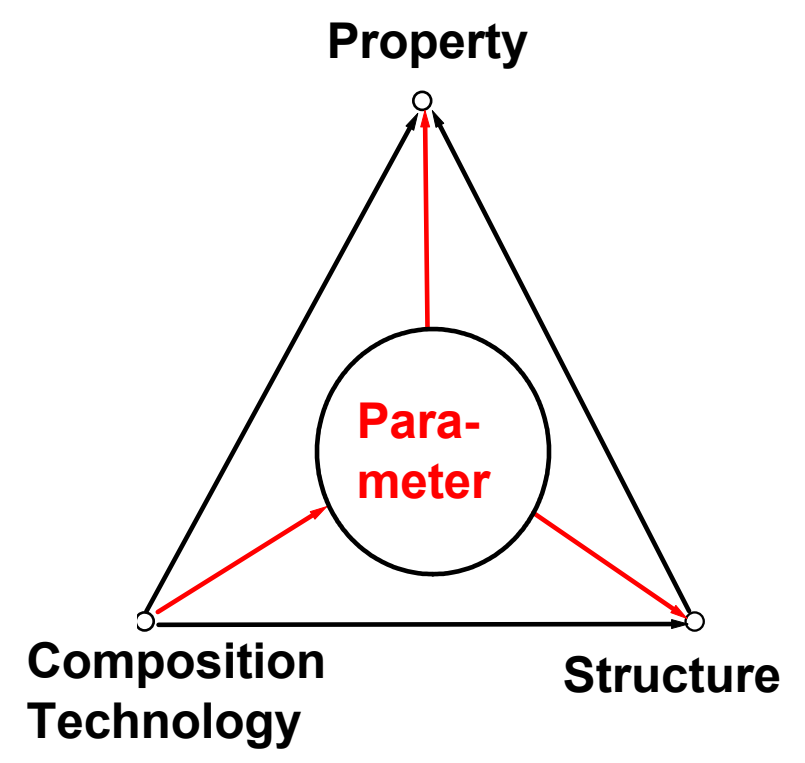

Figure 1. Quaternion "composition-parameter-structure-property".

\subsection{Relationship "Structure-Property" for Piezoelectric Crystals}

In accordance with the Neumann principle, the symmetry group of any physical property includes all crystal point symmetry elements $[11,37,62]$. Consequently, the first essential characteristic of a triad is the relation "structure-property". The set of the properties is specified by the 32-point crystal symmetry, and there is a simple, full one-to-one correspondence between the crystallographic structure and a set of possible physical properties of crystals $[10,37]$. So, it is possible to create a full classification of the crystals on this basis $[10,37]$.

The acentric crystals include 21-point symmetry structures, among which only piezoelectric crystals are mainly used now at the creation of optoelectronic devices [2,3]. These crystals have 20-point symmetry structures (Figure 2) [9,10,37,62]. They were also divided into 6 affine groups (vertical column) according to a specific combination of their acentric properties (Figure 2) [10,37]. There are four acentric properties: piezoelectricity, polarity, optical activity and enantiomorphism $[10,37,61]$. The set of piezoelectric crystals includes 10 polar (pyroelectric) and 10 nonpolar (pure piezoelectric) structures. Part of the polar crystals can be ferroelectrics. Each piezoelectric crystal has nonlinear optical (NLO) and electro-optical (EO) properties [37,62]. The crystals of the sixth affine group have only one acentric property: piezoelectricity (NLO-, and EO). The crystals of the first affine group have two acentric properties: piezoelectricity and polarity. The crystals of the second affine group have three acentric properties: piezoelectricity, polarity and optical activity. The crystals of the third affine group have all acentric properties: piezoelectricity, optical activity, enantiomorphism and polarity. The nonpolar crystals of the fourth affine group have three acentric properties: piezoelectricity, optical activity and enantiomorphism. The crystals of the fifth affine group have two acentric properties: piezoelectricity and optical activity. So, the crystal of each selected affine group has a clearly determined, simple set of acentric properties. Besides, 20 piezoelectric crystals can be divided into 7 horizontal lines according to the crystal system: higher (cubic), middle (hexagonal, tetragonal, rhombohedral) and lower (rhombic, monoclinic, triclinic (anorthic) (Figure 2). Consequently, the cubic crystals have one light refraction index; the hexagonal, tetragonal, rhombohedral-two refraction indexes, and the rhombic, monoclinic, triclinic-three refraction indexes. 


\begin{tabular}{|c|c|c|c|c|c|c|}
\hline \multirow[b]{2}{*}{$\mathrm{C}_{6 \mathrm{v}}$} & \multirow{3}{*}{$\begin{array}{l}\text { Para- } \\
\text { elastic }\end{array}$} & & $\mathrm{T}$ & & \multicolumn{2}{|c|}{\begin{tabular}{l|l}
$\mathrm{T}_{d}$ & Cub1c \\
\end{tabular}} \\
\hline & & $\mathrm{C}_{6}$ & $\mathrm{D}_{6}$ & & $\mathrm{D}_{3 \mathrm{~h}}, \mathrm{C}_{31}$ & Hex agonal \\
\hline $\mathrm{C}_{4 \mathrm{v}}$ & & $\mathrm{C}_{4}$ & $\mathrm{D}_{4}$ & \begin{tabular}{|l|l|}
$\mathrm{D}_{2 \mathrm{~d}}$ & $\mathrm{~S}_{4}$ \\
\end{tabular} & & Tetrag onal \\
\hline $\mathrm{C}_{3 \mathrm{v}}$ & & $\mathrm{C}_{3}$ & $\mathrm{D}_{3}$ & & & Rhombohedra. \\
\hline \multirow{3}{*}{$\begin{array}{l}\text { Ferro- } \\
\text { elastic }\end{array}$} & $\mathrm{C}_{2 \mathrm{v}}$ & & $\mathrm{D}_{2}$ & & & Rhombic \\
\hline & $\mathrm{C}_{8}$ & $\mathrm{C}_{2}$ & & & & Monoclinic \\
\hline & & $\mathrm{C}_{1}$ & & & & Triclinic \\
\hline I & II & III & IV & $\mathrm{V}$ & VI & \\
\hline \multicolumn{7}{|c|}{ Enantiomorphic, EM } \\
\hline & \multicolumn{4}{|c|}{ Optical active, $\mathrm{OA}$} & & \\
\hline \multicolumn{7}{|c|}{ Polar, ferroelectric Nonpolar, piezoelectric } \\
\hline
\end{tabular}

Figure 2. Table (scheme) of interrelationship "structure-property" for all piezoelectric crystals.

According to Aizu [37,63], the horizontal dashed stepped line defines the boundary between the NCS ferroelastic (below, yellow) and paraelastic crystals (above, grey). The existence of ferromagnetic (segneto-magnetic) properties among the polar crystals of the third affine group, polar structure $\mathrm{C}_{\mathrm{s}}$ and nonpolar ferromagnetic structures $\mathrm{S}_{4}, \mathrm{C}_{3 \mathrm{~h}}$ were also taken into account earlier in the general scheme of relation "structure-property". The CS crystals are also divided into two groups of ferroelastic and nonferroelastic crystals, which are also divided into ferromagnetic (FM) and nonferromagnetic subgroups [37].

Among the known acentric binary oxides, high prevalence is observed for some structures: rhombic $C_{2 v}$ (up to $25 \%$ ), cubic $T_{d}(20 \%)$, then monoclinic $C_{s}$, rhombohedral $C_{3 v}$, tetragonal $D_{2 d}$, rhombic $D_{2}$, monoclinic, $C_{2}$, and the very rare structures are $C_{3 h}$ and $C_{4}[37,42]$. These distributions are dependent on the nature of chemical bonds in different crystals and, consequently-on the classes of chemical compounds [38-56].

So, further, we shall repeatedly discuss the empiric mutual comparison of the interrelationship between the values of the main acentric properties: piezoelectric coefficient (d), nonlinear optical susceptibility $\left(\chi^{(2)}\right)$ and electro-optical coefficient $(r)$ for binary and ternary oxide crystals [57].

\section{Mutual Comparison of the Main Acentric Properties}

\subsection{General}

The set of the main acentric properties (" $\chi^{(2) ",}, " r$ ", and " $d$ ") has the same tensor representation for crystals with a different point symmetry $[2,12,13,37,62]$. The quantitative relation between these values can be presented as some defined analytical expression for the predetermined chemical classes of materials [13]. Besides, electro-optical properties (r), such as, particularly, the nonlinear optical process [64] was discussed. At present, an empirical rough estimation of nonlinear optical susceptibility $\chi^{(2)}$ for novel crystals by the laser-powder comparative method, using the known standard crystal (Kurtz-Perry method) [65], is very useful But the estimation of other acentric properties is a more laborious task $[2,3,12,13]$. So, the knowledge of the interrelationship between the values of the main acentric properties is of the highest interest for acentric dielectronics, and it is very necessary for a full characterization of functional crystalline materials both at the search of the most optimal materials and at the creation of optoelectronic devices [2,3,13]. Indeed, if the NLO-susceptibility values are estimated, then, further, the quantitative or qualitative knowledge about the corresponding piezoelectric and electro-optic coefficient [2] values is necessary. 
The data on the acentric properties values is collected from reference books, both from our and other papers containing many tabulated data about the interrelationship "compositionstructure-property" for oxide crystals $[2,3,6,10-13,26-55,65-86]$. These tabulated data are quite sufficient; so, in the first approximation, the main acentric properties can be compared mutually. Besides, these $[2,3,31,33]$ have some information about many applications of the oxide crystals in acousto-electronics and optoelectronics.

The empiric mutual interrelations of acentric properties have, as a rule, some or essential data scattering, since they are related to different crystals, having various compositions, diverse structure and compound chemical bonds. Nevertheless, the clear upper boundaries (envelope) of such interrelations have always been plotted. Consequently, the more complete knowledge about the indistinct correlations of such values is highly necessary for the prediction of possible efficient optoelectronic devices [2,3]. Three examples of such analysis in the sequences of nonlinearity, increasing in the plotted empiric dependences [57], are presented below.

\subsection{Correlation between "Electro-Optical and Piezoelectric Properties"}

The piezoelectric coefficient (d) values for the Rachel salt crystal equals 800-2300 pC/N, for the $\mathrm{PbTiO}_{3}$ crystal-580 $\mathrm{pC} / \mathrm{N}$, for the $\mathrm{BaTiO}_{3}$ crystal-587 $\mathrm{p} / \mathrm{CN}$, for the $\mathrm{Pb}\left(\mathrm{Mg}_{1 / 3} \mathrm{Nb}_{2 / 3}\right) \mathrm{O}_{3}-\mathrm{PbTiO}_{3}$ crystal-2500 $\mathrm{pC} / \mathrm{N}$; the electro-optical coefficient for the $\mathrm{KNbO}_{3}$ crystal equals $450 \mathrm{pm} / \mathrm{V}$, for the $\mathrm{BaTiO}_{3}$ crystal $1640 \mathrm{pm} / \mathrm{V}$ and for the $\mathrm{Ba}_{0.25} \mathrm{Sr}_{0.75} \mathrm{Nb}_{2} \mathrm{O}_{6}$ crystal $1410 \mathrm{pm} / \mathrm{V}[12,13,27-30,70-72]$. Therefore, the expression $\operatorname{lgr}=\mathrm{f}(\operatorname{lgd})$ for the relation between the maximal "electro-optical and piezoelectric coefficient" values, including 13 piezoelectric structures, is presented on the logarithmic scale in Figure 3.

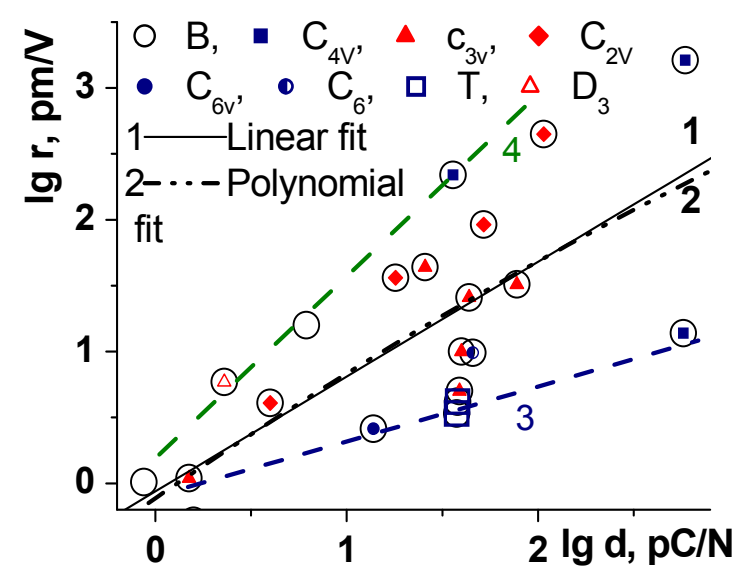

Figure 3. Correlation between the values " $\mathrm{r}$ " and " $\mathrm{d}$ " for binary and ternary oxide crystals. Line 1 is the mean linear correlation, 2-close to linear, nonlinear quadric correlation. Data B-all data.

Here, in spite of the high point scattering, the simple linear correlation "lgd-lgr" with "lgr", increasing from some positive proportional values "lgd", is roughly observed. The maximal values of " $\mathrm{r}$ ", and " $\mathrm{d}$ ", as rule, are related to polar ferroelectric structures (dark symbols) in Figure 3. The same linear correlation can be plotted here as for both the upper boundary and the lowest boundary of this set of data $\{\operatorname{lgr}, \operatorname{lgd}\}$, Figure 3, Line 4 and 3 . Line 2 for the mean values of the data set is also very close to the straight line.

Besides, it is necessary to note that the giant enhancement of some "acentric" property is observed, as rule, for a certain value of spontaneous polarization, piezoelectric, electro-optical, nonlinear optical susceptibility or the optical activity of oxide crystals [81,87-90]. The optical activity is increased for the crystals with the langasite structure $[82,89]$. Such giant enhancement can be stipulated by the cavity resonance effect in the nonlinear photonic crystals, by the cross-correlation between magnetic and 
electric properties (particularly in the $\mathrm{BiFeO}_{3}$ films [88]), by the second-order Jahn Teller effect, and by the enhancement of piezoelectric property near the morphotropic phase boundary (MPB) [72-77].

\subsection{Correlation between "Electro-Optical and Nonlinear Optical Properties"}

The extreme relation between the maximal values of "electro-optical and nonlinear optical coefficients", which includes 16 piezoelectric structures, is presented in Figure 4. A clear maximum of the upper envelope for the empirical formula of dependence " $\chi^{(2)}=F(\ln r)^{\text {" }}$ at the values of $\mathrm{r}=15-30 \mathrm{pm} / \mathrm{V}$ is observed here. So, the interrelationship "electro-optical coefficient, lnr-NLO susceptibility, $\chi^{(2) "}$ is clearly related to the quadric dependence at the comparison with simple linear expression "ln r-ln d" (line 1), Figures 3 and 4.

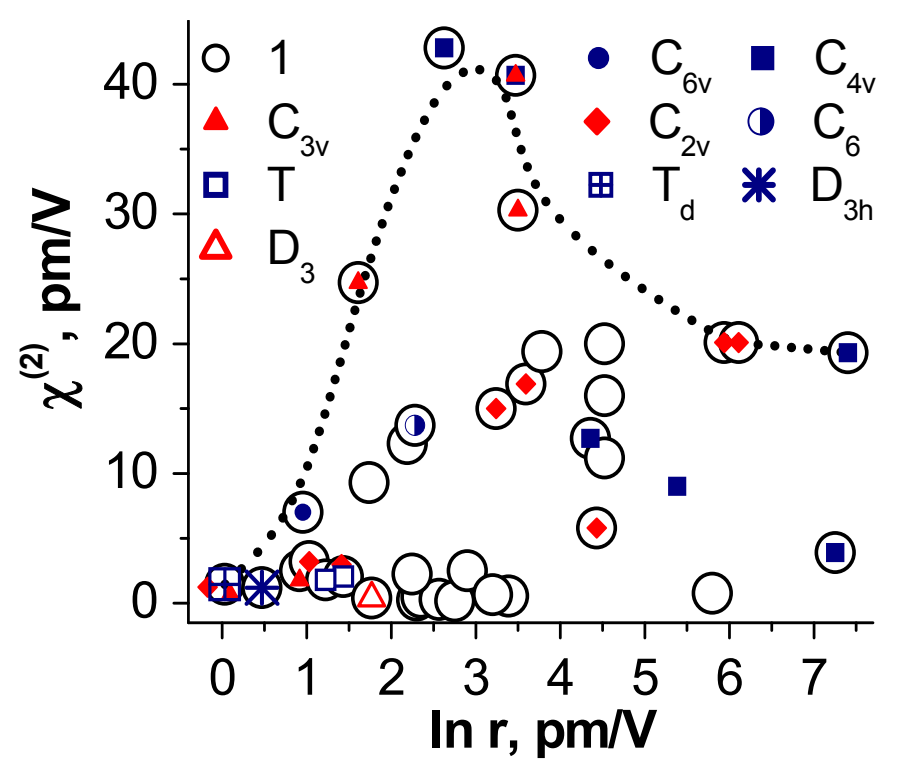

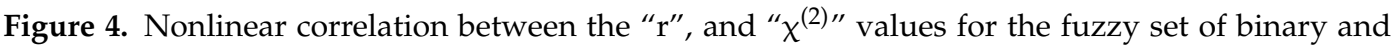
ternary oxide crystals. The line is the upper envelope for fuzzy point set $\left\{\chi^{(2)}-\mathrm{r}\right\}$.

Despite the high data scattering, the extreme expression for the fuzzy dependence " $r-\chi^{(2)}$ " is quite reliable in the first approximation. The maximal values of " $r$ ", and " $\chi(2)$ " are also related to crystals of polar ferroelectric structures (Figures 3 and 4). Such extreme correlation is not discussed in the modern theory of nonlinear optical and electro-optical properties of dielectric crystals [2,12,13].

\subsection{Correlation between "Piezoelectric and Nonlinear Optical Properties"}

The most nonlinear expression is observed in the empiric correlation between NLO- and piezoelectric properties of oxide crystals (Figure 5). Here, the upper envelope of the weak fuzzy empirical-formula dependence $\chi^{(2)}=\mathrm{F}(\mathrm{d})$ (B-spline line) is plotted for the set of simple and binary oxides. This line has its maximum at some average " $\mathrm{d}$ " values. Here, at the plotting of B-spline line, some points with a high level of values $\chi^{(2)}>53 \mathrm{pm} / \mathrm{V}$ for oxide crystals $\mathrm{ZnTiO}_{3}, \mathrm{PbVO}_{3}, \mathrm{BiGaO}_{3}$, $\mathrm{BiFeO}_{3}, \beta-\mathrm{LiNbWO}_{6}$ are not taken into account because of the absence of their data on the piezoelectric coefficient $[68,76-79,84-86]$. In Figure 5, the maximal values of $\chi^{(2)}$ are plotted for oxide crystals $\mathrm{PbVO}_{3}$ $\left(53 \mathrm{pm} / \mathrm{V}, \mathrm{C}_{4 \mathrm{v}}\right)$ [68], $\beta-\mathrm{LiWNbO}_{6}\left(\chi^{(2)} \approx 70 \mathrm{pm} / \mathrm{V}, \mathrm{C}_{3 \mathrm{~V}}\right)$ [78-89], and our estimation of the values $\chi^{(2)}$ for crystals $\mathrm{ZnTiO}_{3}\left(\mathrm{C}_{3 \mathrm{v}}\right)$ on the last $\mathrm{P}_{\mathrm{s}}$ data [76] is also taken into account But, the higher $\chi^{(2)}$-level for the B-spline line very well corresponds to the $\chi^{(2)}$-level of these points. Now the most giant nonlinear optical coefficient $\mathrm{d}_{33}=3401 \mathrm{pm} / \mathrm{V}$ is observed in the multiferroic $\mathrm{BiFeO}_{3}$ films due to the large ferroelectric polarization $\left(\mathrm{P}_{\mathrm{s}}=100 \mu \mathrm{C} / \mathrm{cm}^{2}\right)$ and coupling between magnetic and ferroelectric order parameters [88]. 


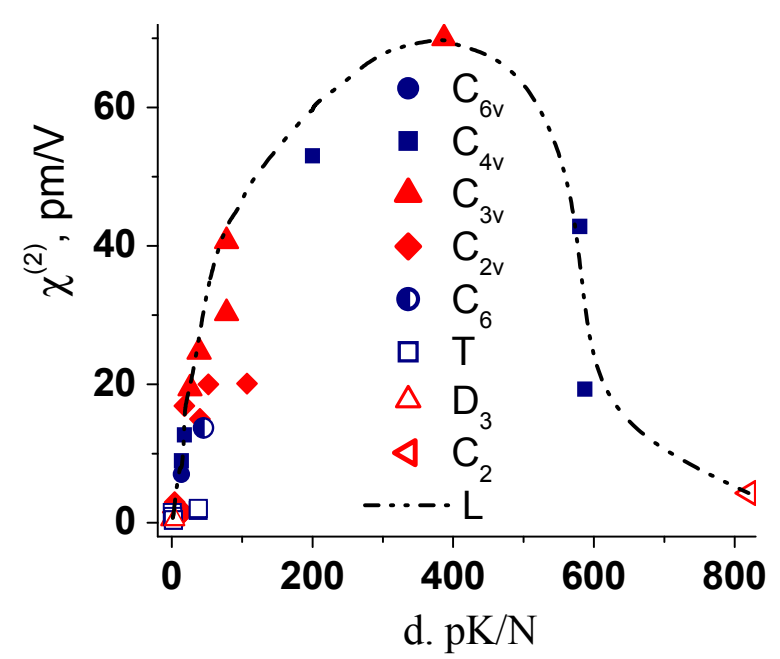

Figure 5. Clear nonlinear correlation between the fuzzy set " $\mathrm{d}$ " and $\chi^{(2)}$ values for binary and ternary oxide crystals. The line is the upper envelope by computer plotting for the fuzzy point set $\left\{\chi^{(2)}-\mathrm{d}\right\}$.

Besides, the maximal values " $\mathrm{d}$ " are found now for crystals solid solutions $\mathrm{PbMg}_{1.3} \mathrm{Nb}_{2} / \mathrm{O}_{3}-\mathrm{BaTiO}_{3}(2500 \mathrm{pC} / \mathrm{N})$ [72-74]. But, the estimation of NLO-susceptibility $\chi^{(2)}$ in these crystals is very small $\left(\chi^{(2)}<3-4 \mathrm{pm} / \mathrm{V}\right)$ [72]. Further, the low values of $\chi^{(2)}=4.3 \mathrm{pm} / \mathrm{V}$ for the crystal of Rochelle salt (potassium-sodium tartar, $\mathrm{d} \approx 820-2300 \mathrm{pK} / \mathrm{N}$ )) [12] are taken into account The right slope of D-spline line is formed also by points $\mathrm{d}=1410 \mathrm{pC} / \mathrm{N}, \chi^{(2)} 3.9 \mathrm{pm} / \mathrm{V}$ for $\mathrm{Ba}_{0.25} \mathrm{Sr}_{0.75} \mathrm{Nb}_{2} \mathrm{O}_{6}$ crystal $\left(\mathrm{C}_{4 \mathrm{v}}\right), \mathrm{d}=587 \mathrm{pC} / \mathrm{N}, \chi^{(2)} 19.3 \mathrm{pm} / \mathrm{V}$ for BaTiO 3 crystals $\left(\mathrm{C}_{4 \mathrm{v}}\right), \mathrm{d}=580 \mathrm{pC} / \mathrm{N}$, $\chi^{(2)} 42.8 \mathrm{pm} / \mathrm{V}$ for $\mathrm{PbTiO}_{3}$ crystals $\left(\mathrm{C}_{4 \mathrm{v}}\right)[12,28,30,45,51]$.

Up to now, a direct linear relation between the values of more similar acentric properties is expected. But real empiric correlations between nonlinear optical and electro-optical, or nonlinear optical and piezoelectric properties are strong nonlinear (Figures 4 and 5), while the correlation of piezoelectric and electro-optical properties is clearly linear (Figure 3). Besides, the low boundary of correlation $\chi^{(2)}=\mathrm{F}(\mathrm{r})$ is close to the zero line, while the low boundary of correlation $\lg r=\mathrm{F}(\lg \mathrm{d})$ is clearly linear and it does not equal zero. The revealed empiric interrelationships of acentric properties for oxide crystals are stipulated by the taxonomy of their atomic structure on the crystalline lattice and electronic subsystem, i.e., some acentric properties are predetermined mainly by the crystalline lattice, others-by the electron crystalline subsystem $[13,28,29]$. But, there are some cases of the crystalline lattice interaction with the electron crystalline subsystem. Namely, the nonlinear interrelationship of "electro-optical and nonlinear optical properties" (Figure 4) and also "piezoelectric-nonlinear optical properties" (Figure 5) are observed in the last case. Such clear extreme correlation has not been completely explained so far by the modern theory of nonlinear optical and electro-optical properties of dielectric crystals $[2,12,13,28,29]$. Besides, a more detailed theoretical analysis of the intrinsic localized modes ("breathers") in glasses and unharmonic (noncentrosymmetric) crystals is necessary now for the expanded characterization of different optoelectronic materials [91].

\section{Interrelationship "Fusibility-Hardness-Thermal Conductivity"}

Hard oxide materials, including minerals, have many applications, such as abrasive, precious stone, refractory, building and instrument-making materials [92-95]. Hardness is also the simplest diagnostic property at mineral characterization [94]. At present, hard and refractory oxide crystals are the main materials at the creation of power solid state laser systems [2,4]. For this purpose, the crystalline laser elements must also be high heat-conducting materials [2,4,96]. Besides, many oxide piezoelectric sensor and other materials must have their stable physical properties in a large temperature interval [31]. So, the knowledge of the quantitative relation between the values of melting temperature $\left(\mathrm{T}_{\mathrm{m}}\right)$, hardness $\left(\mathrm{H}_{\mathrm{s}}\right)$ and thermal conductivity $(\boldsymbol{k})$ is necessary at the search and 
selection of different oxide crystals as laser or sensor elements [57]. There are still insufficient data on " $k$ " values [96]. Therefore, in this work, a mutual comparison of the empiric values of the melting temperature, hardness, and thermal conductivity only for the crystals with the known " $k$ " values is carried out. But, further, the essentially more complete crystal oxide data set $\left\{\mathrm{H}_{\mathrm{s}}-\mathrm{T}_{\mathrm{m}}\right\}$ can be compared in detail, taking into account the crystal point symmetry (Figure 6) [58].

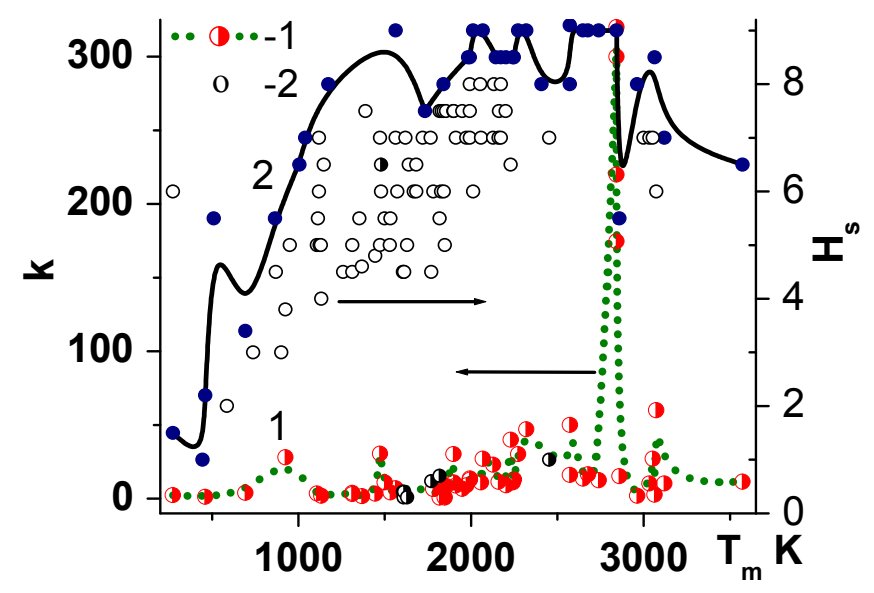

Figure 6. Correlations: 1-“thermal conductivity (k)-melting temperature, $\mathrm{T}_{\mathrm{m}}$ ”. $2{ }^{-}{ }^{\text {"Hardness }}$ $\mathrm{H}_{\mathrm{s}}$-melting temperature". $\mathrm{H}_{\mathrm{s}}-\mathrm{Mohs}, \mathrm{k}-\mathrm{W} / \mathrm{m} \cdot \mathrm{K}$.

The initial data include the physical and structural properties values for many oxide nonlinear optical and laser crystals, and minerals [2,4,6,30,58,92-97]. The fuzzy data set is collected from many reference books for each oxide, as a rule, at room temperature [30,92-97]. In Figure 6 the $\left\{\mathrm{H}_{\mathrm{s}}-\mathrm{T}_{\mathrm{m}}\right\}$, $\left\{k-T_{m}\right\}$-correlations are established only for the crystals with the known " $k$ "value.

Both correlations are similar, the non-monotonic function of the oxide melting temperature having the same four clear main maxima and one shelf for the set $\left\{\mathrm{H}_{\mathrm{s}}-\mathrm{T}_{\mathrm{m}}\right\}$, lines 1-2 (Figure 6). Here at $\mathrm{T}_{\mathrm{m}}$ $273 \mathrm{~K}$, the $\mathrm{H}_{\mathrm{s}}=1.5 \mathrm{Mohs}$ for the ice crystals is present, and the same point $\mathrm{H}_{\mathrm{s}}-6$ Mohs corresponds to the ice measured temperature $<213 \mathrm{~K}$. It is seen that the most refractory oxides have not the highest hardness and thermal conductivity. The most refractory oxide is mineral thorianite, $\mathrm{ThO}_{2}, \mathrm{~T}_{\mathrm{m}}=3573 \mathrm{~K}$ (Figure 6). The higher hardness level is equal to $9 \mathrm{Mohs}$, and it is observed for $\sim$ ten simple and binary oxides having their melting temperature in an interval $1973-2843 \mathrm{~K}\left(\mathrm{AlTaO}_{3}\right.$, alumotantit, $\mathrm{D}_{2 \mathrm{~h}}-\mathrm{BeO}$, $\left.\mathrm{C}_{6 \mathrm{v}}\right)$, and one binary oxide, zinc meta-borate, $\mathrm{Zn}_{4} \mathrm{~B}_{6} \mathrm{O}_{13}, \mathrm{~T}_{\mathrm{m}} \geq 1563 \mathrm{~K}[97,98]$. The hardest simple oxide is $\mathrm{Cr}_{2} \mathrm{O}_{3}$ (mineral eskolaite), $\mathrm{T}_{\mathrm{m}}=2573 \mathrm{~K}, \mathrm{H}_{\mathrm{s}} \sim 9.1$ ). The point symmetry of the hardest oxides is rhombic $\mathrm{D}_{3 \mathrm{~d}}, \mathrm{D}_{2 \mathrm{~h}}$ or cubic $\mathrm{T}_{\mathrm{h}}$. But the $\mathrm{BeO}$ crystal, mineral bromellite, is noncentrosymmetric (NCS, $\mathrm{C}_{6 \mathrm{v}}$ ).

The $\left\{\mathrm{H}_{\mathrm{s}}-\mathrm{T}_{\mathrm{m}}\right\}$-interrelationship for the full set of oxide crystals with different centrosymmetric (CS) and noncentrosymmetric (NCS) polar structures is presented in Figure 7. It is clearly seen that such representation of the function, $\mathrm{H}_{\mathrm{s}}=\mathrm{F}\left(\mathrm{T}_{\mathrm{m}}\right)$ is indistinct, and the $\left\{\mathrm{H}_{\mathrm{s}}-\mathrm{T}_{\mathrm{m}}\right\}$ set is fuzzy. But this set has a well-defined boundary. Namely, the external boundary of the set is restricted with a seven side polygon (Figure 7). The initial point of lines 1, 7 is the melting temperature of oxygen $\mathrm{O}_{2}, \mathrm{~T}_{\mathrm{m}}=54.8$ $\mathrm{K}$, while the last point (intersection of line 4-5) is $\mathrm{ThO}_{2}$, mineral thorianite, $\mathrm{T}_{\mathrm{m}}=3573 \mathrm{~K}$ (Figure 7). The function $\mathrm{H}_{\mathrm{s}}=\mathrm{F}\left(\mathrm{T}_{\mathrm{m}}\right)$ has a "shelf" at hardness, $\mathrm{H}_{\mathrm{s}} \approx 9$ in the interval from the melting temperature $\mathrm{Zn}_{4} \mathrm{~B}_{6} \mathrm{O}_{13}, \mathrm{~T}_{\mathrm{m}} \geq 1563$ up to $2843 \mathrm{~K}(\mathrm{BeO})$ (line 3, Figure 7). In Figure 7 all red points designate the NCS polar ferroelastic oxide phases (No. 2-8), and magenta-points-NCS polar and the nonpolar paraelastic phases. 


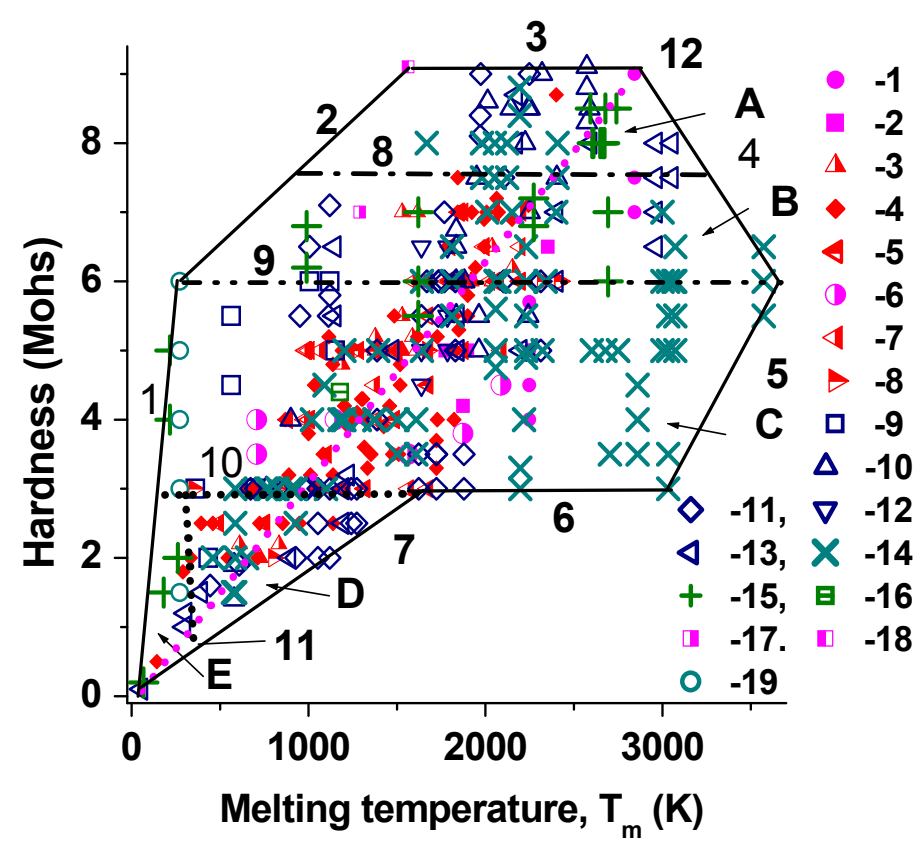

Figure 7. Full fuzzy set of $\left\{\mathrm{H}_{\mathrm{s}}-\mathrm{T}_{\mathrm{m}}\right\}$ for NCS polar (point 1-8), and CS (point 9-16, 19) oxide crystals. $1-\mathrm{C}_{6 \mathrm{v}}, 2-\mathrm{C}_{4 \mathrm{v}}, 3-\mathrm{C}_{3 \mathrm{v}}, 4-\mathrm{C}_{2 \mathrm{v}}, 5-\mathrm{C}_{\mathrm{s}}, 6-\mathrm{C}_{6}, 7-\mathrm{C}_{2}, 8-\mathrm{C}_{1}, 9-\mathrm{D}_{4 \mathrm{~h}}, 10-\mathrm{D}_{3 \mathrm{~d}}, 11-\mathrm{D}_{2 \mathrm{~h}}, 12-\mathrm{C}_{3 \mathrm{i}}, 13-\mathrm{C}_{2 \mathrm{~h}}, 14-\mathrm{O}_{\mathrm{h}}, 15-\mathrm{T}_{\mathrm{h}}$, $16-\mathrm{C}_{4 \mathrm{~h}}, 19-\mathrm{D}_{6 \mathrm{~h}}, 17-18-\mathrm{T}_{\mathrm{d}}, \mathrm{Zn}_{4} \mathrm{~B}_{6} \mathrm{O}_{13}$.

In Figure 7, the CS-ferroelastic phases are designated in navy color, and the paraelastic phases-with dark cyan points. The stroke-dotted magenta-line connects the points of $\mathrm{BeO}$ and $\mathrm{O}_{2}$, and this line is approximately a linear fit for the points of NCS oxides. It is seen that lines 1-4 form a convex boundary, while lines 5-7 form a convexo-concave boundary. It is also seen that NCS oxides are found inside the polygon along line 12, while CS oxides are found inside the polygon and on its boundary. The point for the crystals at " $-60^{\circ} \mathrm{C}$ " forms the angle from lines $1-2$. All the set of oxides is divided with internal lines 8-11 into parts: A, B, C, D, and E. All hardest oxide crystals, having $\mathrm{H}_{\mathrm{s}}=7.5-9.1$, lie in region A. The laser oxide crystals, having the granate-like structure $\mathrm{O}_{\mathrm{h}}$, $\mathrm{H}_{\mathrm{s}}=7.5$, for example $\mathrm{Y}_{3} \mathrm{AL}_{5} \mathrm{O}_{12}$ (YAG), are found in line 8. The oxides, lying on side 3 , are the hardest crystals having $\mathrm{H}_{\mathrm{s}}=8.5-9.1\left(\mathrm{BeO}, \mathrm{Sc}_{2} \mathrm{O}_{3}, \mathrm{Al}_{2} \mathrm{O}_{3}, \mathrm{Ga}_{2} \mathrm{O}_{3}, \mathrm{Y}_{2} \mathrm{O}_{3}, \mathrm{Cr}_{2} \mathrm{O}_{3}, \mathrm{Lu}_{2} \mathrm{O}_{3}, \mathrm{Gd}_{2} \mathrm{O}_{3}\right.$ and other $\mathrm{Rz}_{2} \mathrm{O}_{2}$ ( $\mathrm{Rz}$ - rare-earth element).

These simple oxides form many other binary oxide crystals having $\mathrm{H}_{\mathrm{s}}=8.5-9: \mathrm{BeAl}_{2} \mathrm{O}_{4}, \mathrm{BeGa}_{2} \mathrm{O}_{4}$ ， $\mathrm{AlGaO}_{3}, \mathrm{YAlO}_{3}, \mathrm{YGaO}_{3}, \mathrm{ScAlO}_{3}$, and so on. The point symmetry of these crystals is rhombic $\left(\mathrm{D}_{2 \mathrm{~h}}\right)$, trigonal $\left(\mathrm{D}_{3 \mathrm{~d}}\right)$ or cubic $\mathrm{T}_{\mathrm{h}}, \mathrm{O}_{\mathrm{h}}$. These crystals have mixed ionic-covalent chemical bonds [95]. The oxide crystal with $\mathrm{H}_{\mathrm{s}}=6-7.5$ lies in region $\mathrm{B}$. Here, some oxides have also mixed chemical bonds: e.g., oxides $\mathrm{TeO}_{2}, \mathrm{Tl}_{2} \mathrm{O}_{3}, \mathrm{Bi}_{2} \mathrm{O}_{3}$ have not only "metal-oxygen" bonds, but also intermetallic bonds " $\mathrm{Te}-\mathrm{Te}$ ", "Tl- $\mathrm{Tl}$ ", "Bi-Bi". The crystals having average $\mathrm{H}_{\mathrm{s}} \sim 3-6$ values lie in region $\mathrm{C}$. In line 9, the ice crystal $\left(\mathrm{H}_{2} \mathrm{O}\right)$ at " $-60{ }^{\circ} \mathrm{C}^{\prime}$ with $\mathrm{H}_{\mathrm{s}}=6 \mathrm{Mohs}$ is found, while, near the melting temperature, the ice crystal has $\mathrm{H}_{\mathrm{s}} \sim 1$. In solid ice, ions $\mathrm{H}^{+1}$ and $\mathrm{O}^{-2}$ form strong covalent bonds of both moderate hydrogen bonds. Besides, many oxide crystals have ionic chemical bonds in this region. The oxide crystals, lying in region D, have weak chemical bonds, e.g., crystal-hydrates, ADP and others. The oxide crystals, lying in region E, have the least stable chemical bonds, which form molecular crystalline lattices. Many organic crystals are found here.

The local maximum " $\mathrm{k}$ " at $925 \mathrm{~K}$ corresponds to the monoclinic $\left(\mathrm{C}_{2}\right)$ crystals of $\mathrm{U}_{2} \mathrm{O}_{3}$ $(\mathrm{k}=28 \mathrm{~W} / \mathrm{m} \cdot \mathrm{K})$, and at $\mathrm{T}_{\mathrm{m}}=3573 \mathrm{~K}$-cubic crystals of $\mathrm{MgO}$, mineral periclas $(\mathrm{k}=60 \mathrm{~W} / \mathrm{m} \cdot \mathrm{K})$. The values of $\mathrm{k}$ are equal to $40 \div 50 \mathrm{~W} / \mathrm{m} \cdot \mathrm{K}$ for the trigonal crystals of $\mathrm{Cr}_{2} \mathrm{O}_{3}, \mathrm{Al}_{2} \mathrm{O}_{3}$ and the oxides of rare-earth elements $\left(\mathrm{Rz}_{2} \mathrm{O}_{3}\right)[58,96]$. Besides, the thermal conductivity of $\mathrm{BeO}$ crystals is greater by an order of magnitude than this value for other oxides (Figure 7, curve 1). This value is compared to $k$ 
values for some nonoxide crystals: silicon carbide, diamond $\left(\mathrm{H}_{\mathrm{s}}=10, k=1000 \mathrm{~W} / \mathrm{m} \cdot \mathrm{K}, \mathrm{T}_{\mathrm{m}} \approx 4000 \mathrm{~K}\right)$ and also for copper.

So, the crystal phase properties are determined by the nature of chemical bonds, and the interrelationship between these properties is of multifactor character $[2,12,13,29,58]$. Therefore, the correlation between two physical properties is always a fuzzy function and the sets of $\left\{\mathrm{H}_{\mathrm{s}}-\mathrm{T}_{\mathrm{m}}\right\},\left\{\mathrm{k}-\mathrm{T}_{\mathrm{m}}\right)$ are also fuzzy. Nevertheless, the knowledge of the boundary of fuzzy sets is useful for these sets taxonomy. Besides, a more detailed understanding of interrelationship "composition-structure-property" is needed for the development of modern material science and mineralogy $[1,12,13]$. The suggested analysis of interrelationship $\left\{\mathrm{H}_{\mathrm{s}}-\mathrm{T}_{\mathrm{m}}\right\},\left\{\mathrm{k}-\mathrm{T}_{\mathrm{m}}\right)$ can be further expanded at the accumulation of new data about crystal properties.

The unique hard binary oxide crystal is zinc metaborate, $\mathrm{Zn}_{4} \mathrm{~B}_{6} \mathrm{O}_{13}$ (cubic structure- $\mathrm{T}_{\mathrm{d}}$ ) [98]. Its hardness $\left(\mathrm{H}_{\mathrm{s}}\right)$ equals $\geq 9$ Mohs [99], or $\mathrm{H}_{\mathrm{s}} \geq 7$ [98,100], the melting temperature $=1272-1290 \mathrm{~K}$, the thermal conductivity coefficient $\mathrm{k}=30.54 \mathrm{w} \cdot \mathrm{m}^{-1} \cdot \mathrm{K}^{-1}[98,100]$. But a sharp dependence of the $\mathrm{Zn}_{4} \mathrm{~B}_{6} \mathrm{O}_{13}$ melting temperature $\mathrm{T}_{\mathrm{m}}$ on chemical composition is observed. The true melting temperature is still more than $1200{ }^{\circ} \mathrm{C}$ on our data, because the $\mathrm{Zn}_{4} \mathrm{~B}_{6} \mathrm{O}_{13}$ powder does not sinter at $1200{ }^{\circ} \mathrm{C}$. This crystal is perspective for many investigations and applications in thermo-physics, microelectronics and optoelectronics [2-4,96-98]. Particularly, the perfect $\mathrm{Zn}_{4} \mathrm{~B}_{6} \mathrm{O}_{13}$ crystal growth can allow obtaining new oxide lasers, abrasive, precious stone materials.

The suggested analysis of interrelationship $\left\{\mathrm{H}_{\mathrm{s}}-\mathrm{T}_{\mathrm{m}}\right\},\left\{\mathrm{k}-\mathrm{T}_{\mathrm{m}}\right)$ can be further expanded by the accumulation of new data for new crystal properties.

\section{Interrelationship “Composition- Tructure-Oxide Bond Length-NLO-Susceptibility" for Binary Oxide Crystals}

Earlier, in some contributions, we carried out such study of the empirical relation "oxide bond length-structure-NLO property" for binary oxide crystals, since it is the simplest and essential version in the following understanding of the problem $[38,42,43]$. For this goal, a data set on the structure, oxide bond lengths and NLO susceptibility about $>720$ NCS binary oxide crystals, for which the crystal structure had been refined by the experimental methods of X-ray and neutron analysis (Supplementary information, Table S1), was compiled. The chemical composition of binary oxides can be described by formulas $\mathrm{M}_{\mathrm{n}} \mathrm{M}_{\mathrm{m}} \mathrm{O}_{\mathrm{t}}, \mathrm{M}_{\mathrm{n}} \mathrm{E}_{\mathrm{m}} \mathrm{O}_{\mathrm{t}}$ or $\mathrm{E}_{\mathrm{n}} \mathrm{E}_{\mathrm{m}} \mathrm{O}_{\mathrm{t}}$, in which cation types $\mathrm{E}$ and $\mathrm{M}$ are defined by the relation $\sim 120 \mathrm{pm}<L(\mathrm{E}-\mathrm{O}) \leq \sim 202 \mathrm{pm}<L(\mathrm{M}-\mathrm{O})$. At computer plotting, formulas $\mathrm{M}_{\mathrm{m}} \mathrm{M}_{\mathrm{n}} \mathrm{O}_{\mathrm{t}}, \mathrm{M}_{\mathrm{m}} \mathrm{E}_{\mathrm{n}} \mathrm{O}_{\mathrm{t}}$ or $\mathrm{E}_{\mathrm{m}} \mathrm{E}_{\mathrm{n}} \mathrm{O}_{\mathrm{t}}$ are also taken into account to obtain a symmetric figure. All the figure plotting was carried out using the original computer program, version 6.1, according to the tabulated data (Supplementary Materials). The most part of this compound list does not contain the data on many "acentric" properties. Therefore, at plotting correlation "composition-structure-oxide bond length", the crystal symbols are designated, as a rule, in different colors for measurable and non-measurable "acentric" crystal properties, and also for paraelastic or ferroelastic crystals. Besides, the filled or empty symbol is also for designating different structures, and the symbol view also takes in into account a crystal system from the cubic to triclinic symmetry (Syngonie).

First of all, in Figure 8, the rosettes of two ellipses of acentricity are plotted on the plane of oxide bond lengths $L(\mathrm{E}-\mathrm{O})-L(\mathrm{M}-\mathrm{O})$ for piezoelectric binary oxide crystals, having measurable NLO-susceptibility $\chi^{(2)}$. The minimal values of $\chi^{(2)}>0.01 / 0.05 \mathrm{pm} / \mathrm{V}$ are estimated, as a rule, by the Kurtz-Perry method [65]. This data set includes all 20 piezoelectric structures, which contain the crystals of all 6 affine groups, having also measurable piezoelectric and electro-optical properties Figure $8[2,3,38,42,43]$. Points $1-2,6-7$ are for designating polar paraelastic crystals (magentic color), points 3-5, 8-10 designate polar ferro-elastic crystals (red color). 


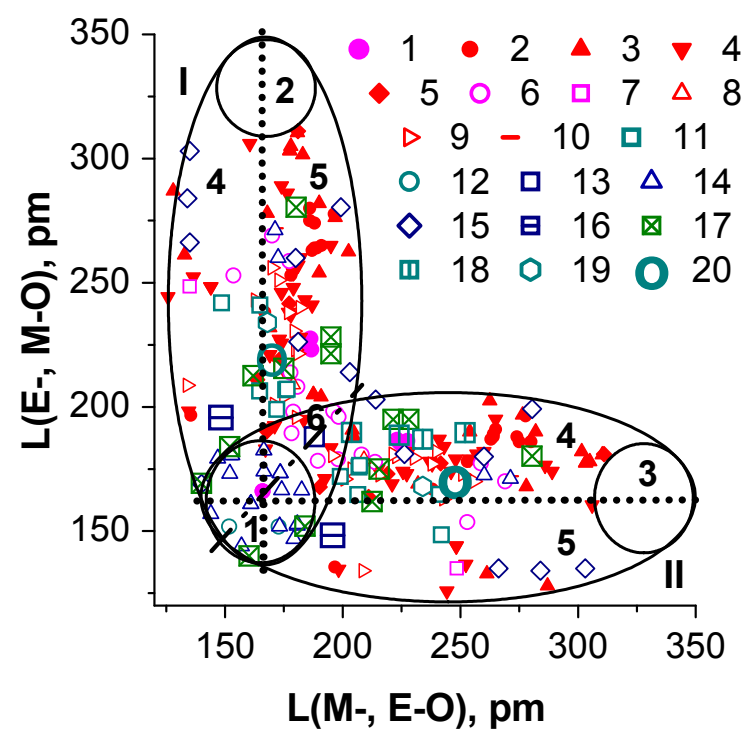

Figure 8. Ellipses of "acentricity" for piezoelectric binary oxide crystals with measurable NLO susceptibility $\chi^{(2)}: 1-\mathrm{C}_{6 \mathrm{v}} ; 2-\mathrm{C}_{4 \mathrm{v}} ; 3-\mathrm{C}_{3 \mathrm{v}} ; 4-\mathrm{C}_{2 \mathrm{v}} ; 5-\mathrm{C}_{\mathrm{s}} ; 6-\mathrm{C}_{6} ; 7-\mathrm{C}_{4} ; 8-\mathrm{C}_{3} ; 9-\mathrm{C}_{2} ; 10-\mathrm{C}_{1} ; 11-\mathrm{T} ; 12-\mathrm{D}_{6} ; 13-\mathrm{D}_{4}$; $14-\mathrm{D}_{3} ; 15-\mathrm{D}_{2} ; 16-\mathrm{D}_{2 \mathrm{~d}} ; 17-\mathrm{S}_{4} ; 18-\mathrm{T}_{\mathrm{d}} ; 19-\mathrm{D}_{3 \mathrm{~h}} ; 20-\mathrm{C}_{3 \mathrm{~h}}$.

All points 1-10 are for designating polar pyro-electric crystals. Points 11-12 designate nonpolar para-elastic crystals (dark cyan color), points 13-16 designate nonpolar ferroelastic crystals (navy color), points 17-20 designate nonpolar paraelastic crystals (dark cyan color).

The ellipse rosette contains the intersecting part of two ellipses (I, II), or "onion", which is divided into a round part (circle 1) and a curvilinear triangle near the upper parts of onion 6 . The upper part of the ellipses, which is empty and does not contain binary oxide crystals with the measurable acentric properties so far, is designated by circles $2-3$. The central part of the ellipse is divided into left and right regions with subfields 4 and 5 . The left part of ellipses I and the lower part of ellipses II in Figure 8 contain the crystals of nitrites, nitrates, carbonates, borates, chlorates and phosphates with weak, moderate, or average NLO properties (subfields 4: $\mathrm{Zn}_{4} \mathrm{O}\left(\mathrm{BO}_{2}\right)_{6}, \mathrm{~T}_{\mathrm{d}}, \chi^{(2)} \sim 0.22-\mathrm{pm} / \mathrm{V}$; $\mathrm{Ba}_{2} \mathrm{~B}_{10} \mathrm{O}_{17}, \mathrm{C}_{1}, \chi^{(2)}>0.2 \mathrm{pm} / \mathrm{V} ; \mathrm{BiB}_{8} \mathrm{O}_{13}, \mathrm{C}_{2}, \chi^{(2)}>0.6 \mathrm{pm} / \mathrm{V} ; \mathrm{PbB}_{4} \mathrm{O}_{7}, \mathrm{C}_{2 \mathrm{v}}, \chi^{(2)}=3.2 \mathrm{pm} / \mathrm{V}, \mathrm{BiB}_{3} \mathrm{O}_{6}$, $\mathrm{C}_{2}, \chi^{(2)}=3.2-\mathrm{pm} / \mathrm{V}, \gamma-\mathrm{LiBO}_{2}, \mathrm{D}_{2 \mathrm{~d}}, \chi^{(2)}=6.3 \mathrm{pm} / \mathrm{V}$ (Supplementary information, Table S1).

The right parts of ellipses I and the upper parts of ellipses II contain the noncentrosymmetric crystals of simple silicates, bromates, selenates, formates, vanadites, molibdates, wolframates, iodates, niobates, titanates. aluminates, tantalates, gallates with weak, moderate, average or high NLO-properties (subfields 5, and 6) (subfields 5, 6: $\beta-\mathrm{TeO}_{2}, \mathrm{D}_{4}, \chi^{(2)}=0.4 \mathrm{pm} / \mathrm{V} ; \mathrm{Bi}_{4} \mathrm{Ge}_{3} \mathrm{O}_{12}, \mathrm{~T}_{\mathrm{d}}$, $\chi^{(2)}=1.46 \mathrm{pm} / \mathrm{V} ; \mathrm{DyTa}_{7} \mathrm{O}_{19}, \mathrm{D}_{3 \mathrm{~h}}, \chi^{(2)}=2.1 \mathrm{pm} / \mathrm{V} ; \mathrm{Tl}_{2} \mathrm{MoO}_{4}, \mathrm{C}_{2}, \chi^{(2)}=5.5 \mathrm{pm} / \mathrm{V} ; \mathrm{TeSeO}_{4}, \mathrm{C}_{\mathrm{s}}$, $\chi^{(2)}=8 \mathrm{pm} / \mathrm{V} ; \alpha-\mathrm{LiIO}_{3}, \mathrm{C}_{6}, \chi^{(2)}=13.7 \mathrm{pm} / \mathrm{V} ; \mathrm{Ca}_{2} \mathrm{Nb}_{2} \mathrm{O}_{7}, \mathrm{C}_{2 \mathrm{v}}, \chi^{(2)}=15 \mathrm{pm} / \mathrm{V} ; \mathrm{KNbO}_{3}, \mathrm{C}_{2 \mathrm{v}}$, $\chi^{(2)}=20.1 \mathrm{pm} / \mathrm{V} ; \mathrm{KIO}_{3}, \mathrm{C}_{3 \mathrm{v}}, \chi^{(2)}=20.1 \mathrm{pm} / \mathrm{V} ; \mathrm{LiNbO}_{3}, \mathrm{C}_{3 \mathrm{v}}, \chi^{(2)}=40.7 \mathrm{pm} / \mathrm{V} ; \mathrm{PbTiO}_{3}, \mathrm{C}_{4 \mathrm{v}}$, $\chi^{(2)}=42.7 \mathrm{pm} / \mathrm{V} ; \mathrm{PbVO}_{3}, \mathrm{C}_{4 \mathrm{v}}, \chi^{(2)}=53.7 \mathrm{pm} / \mathrm{V}$ (Supplementary Materials, Table S1). According to the theoretical and experimental estimation in region 5, the giant resonance NLO-susceptibility $\chi^{(2)}$ for the multiferroic $\mathrm{BiFeO}_{3}$ films $\left|\mathrm{d}_{22}\right|$ is equal to $298.4 \mathrm{pm} / \mathrm{V}[86,88,90]$. It is clearly seen that, in circled region 1 , the nonpolar trigonal $\mathrm{D}_{3}$ crystals are only positioned, while these crystals are rare in other regions.

So, the main conclusion from the presented empirical data is a clear absence of crystals with any measurable piezoelectric, nonlinear optical, and electro-optical properties, being out of "acentricity" ellipses (Figure 8), while there are some NCS crystals in this region determined by the X-ray crystallographic analysis (Supplementary Materials, Table S1) $[38,42,43]$. Namely, all piezoelectric crystals, having measurable NLO-susceptibility $\chi^{(2)}$, are positioned only inside the rosette of two 
ellipses (Figure 8). This simple requirement is not taken into account in [101,102]. Therefore, the predictions of some authors for any "acentric" property for such crystals are not sufficiently correct.

Further on, for the comparison of different crystal groups, all acentricity ellipses for the I-VI affine groups of binary oxide crystals (Figures 9-14) are plotted in a consecutive order. Here, in circles $2-3$, some crystals with the non-measurable, or weak acentric properties are sometimes positioned, and only crystals with the "nonmeasurable" acentric properties are observed out of ellipses. On the coordinate plane, the relative position of the crystals with measurable "acentric" properties is the same as in Figure 8 inside the ellipses of "acentricity". But the crystals with nonmeasurable or with nonestimated "acentric" properties are positioned mainly inside two ellipses, and some location of the crystal with identical structures is observed in designated regions 1-6. For example, the crystals with structures $C_{6 v}$ are positioned in circle 1 , region 6 . The crystals with structures $C_{2 v}$ are positioned mainly near "onion" regions 4-5 (Figure 10), while the crystals with structures $C_{s}$ are observed here in circle 1 and, near this circle, in regions 4 . The crystals with structures $C_{1}, C_{2}, C_{3}$ are positioned mainly inside circle 1, region 6 and near, in the central parts of regions $4-5$ (Figure 11). The crystals with structures $D_{6}, D_{3}$ are positioned mainly inside circle 1 , and the structures $D_{3}$ are also observed near, in the central parts of regions $4-5$ (Figure 12). The crystals with structures $D_{2 d}, S_{4}$ are positioned mainly in the central parts of regions $4-5$ and 6 (Figure 13). The crystals with structures $T_{d}, D_{3 h}$ are positioned mainly in all regions $4-5$ (Figure 14). Circle 1 is empty here. So, there are some problems of "acentric" properties prediction for many oxide crystals which are positioned in the ellipses rosette. But many oxide crystals, positioned inside the ellipses, have also values of "acentric" properties with the level close to zero (Supplementary Materials, Table S1).

Since the values of "acentric" properties are essentially dependent on the size and structure of anions and anionic groups $[14,59,60]$, it is necessary to plot such correlation, $\chi^{(2)}=f(L(E-O))$ for the whole set of the binary oxide crystals (Figure 15). Here, the comparison of piezoelectric crystals, according to interrelation" oxide bond length-NLO susceptibility", is carried out $\left(\chi^{(2)}=\mathrm{f}(L(\mathrm{E}-\mathrm{O}))\right.$. This function is fuzzy, but its upper envelope is nonmonotonic, having a slope maximum at $L(\mathrm{E}-\mathrm{O})$ $\sim 146 \mathrm{pm}$ inside the interval $134<L(\mathrm{EO})<150 \mathrm{pm}$, and three clear maxima at 166,180 and $188 \mathrm{pm}$. It was shown that this circumstance is predetermined by the clear taxonomy of simple oxides on two types with $\sigma-$, and $\pi$-oxide bonds $[14,38,42,43]$. This clear taxonomy is observed also for the ternary crystals. Namely, the crystals of nitrites, nitrates, carbonates, borates, sulfates, phosphates, silicates have their $\pi$-oxide bonds in the anionic complex [103].

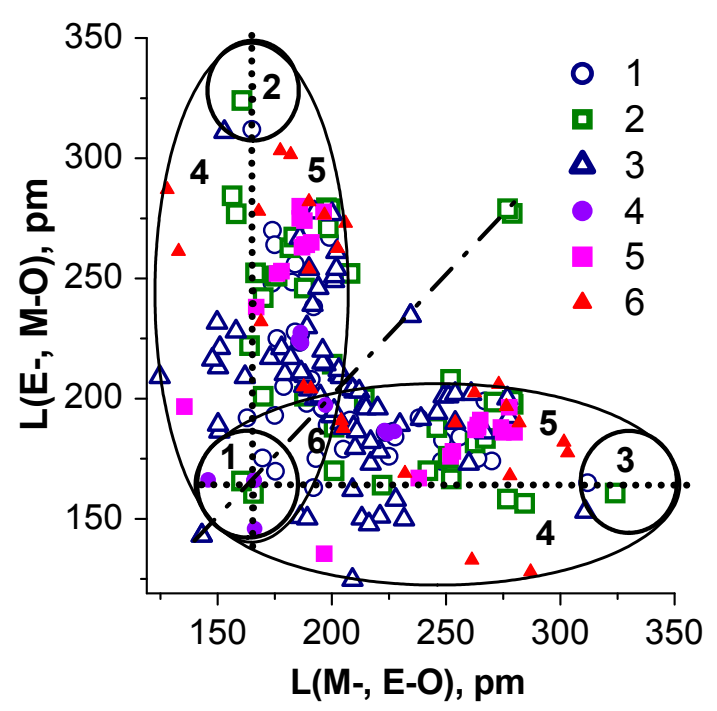

Figure 9. Ellipses of "acentricity" for piezoelectric binary oxide crystals of the first affine group. Crystals with nonmeasurable acentric properties $1-\mathrm{C}_{6 \mathrm{v}} ; 2-\mathrm{C}_{4 \mathrm{v}} ; 3-\mathrm{C}_{3 \mathrm{v}}$. Crystals with measurable acentric properties $4-\mathrm{C}_{6 \mathrm{v}} ; 5-\mathrm{C}_{4 \mathrm{v}} ; 6-\mathrm{C}_{3 \mathrm{v}}$. 


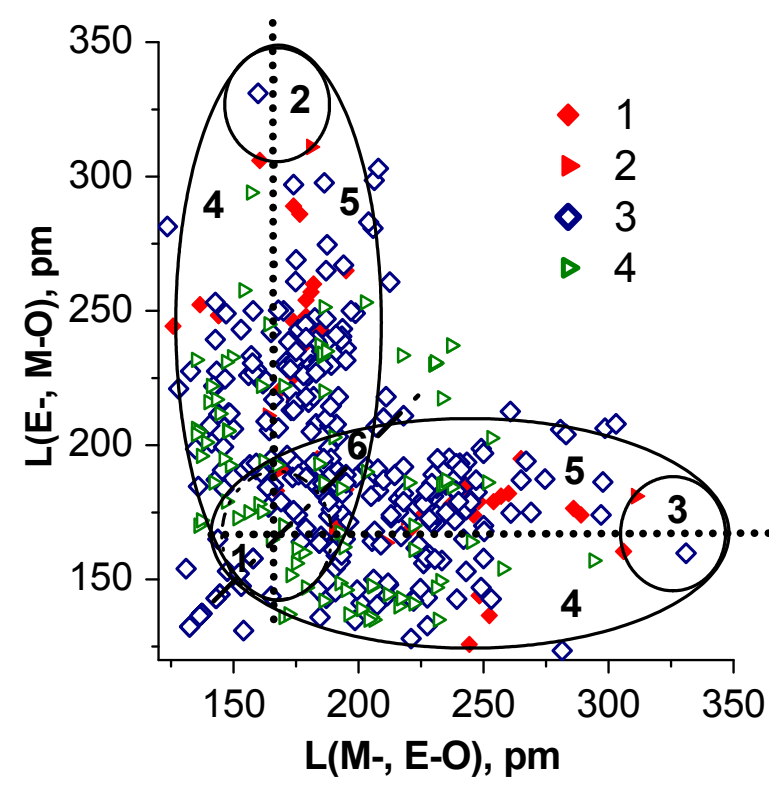

Figure 10. Ellipses of "acentricity" for the piezoelectric binary oxide crystals of affine group II. Crystals with measurable acentric properties: $1-\mathrm{C}_{2 \mathrm{v}} ; 2-\mathrm{C}_{\mathrm{s}}$. Crystals with nonmeasurable acentric properties; $3-\mathrm{C}_{2 \mathrm{v}} ; 4-\mathrm{C}_{\mathrm{s}}$.

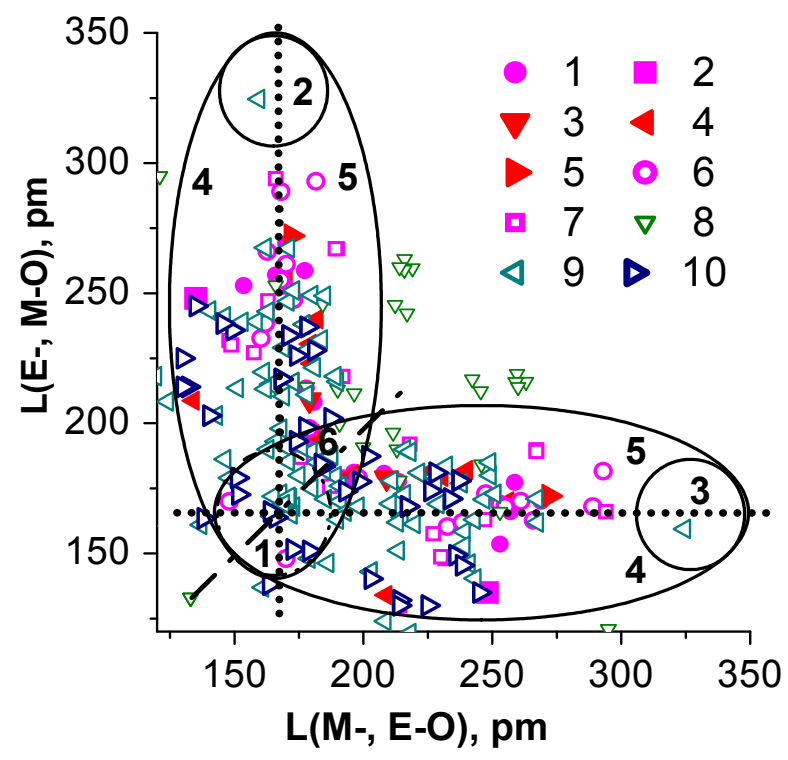

Figure 11. Ellipses of "acentricity" for the piezoelectric binary oxide crystals of affine group III: Crystals with measurable acentric properties: $1-\mathrm{C}_{6} ; 2-\mathrm{C}_{4} ; 3-\mathrm{C}_{3} ; 4-\mathrm{C}_{2} ; 5-\mathrm{C}_{1}$. Crystals with nonmeasurable acentric properties: $6-\mathrm{C}_{6} ; 7-\mathrm{C}_{4} ; 8-\mathrm{C}_{3} ; 9-\mathrm{C}_{2} ; 10-\mathrm{C}_{1}$.

So, for the set of the binary oxide crystals in the interval $124<L(\mathrm{E}-\mathrm{O})<161 \mathrm{pm}$, the oxide compounds of nitrites, nitrates, carbonates, borates, sulfates, phosphates, silicates with $\pi$-oxide bonds, Figure 15 [9] are positioned. In the interval $161<L(\mathrm{E}-\mathrm{O})<202 \mathrm{pm}$, the oxide compounds of chromates, arsenates, vanadates, vanadites, germanates, molybdates, tungstates, iodates, niobates, titanates, tantalates, zincates, zirconates, hafnates crystals the $\sigma$-oxide bonds are positioned. 


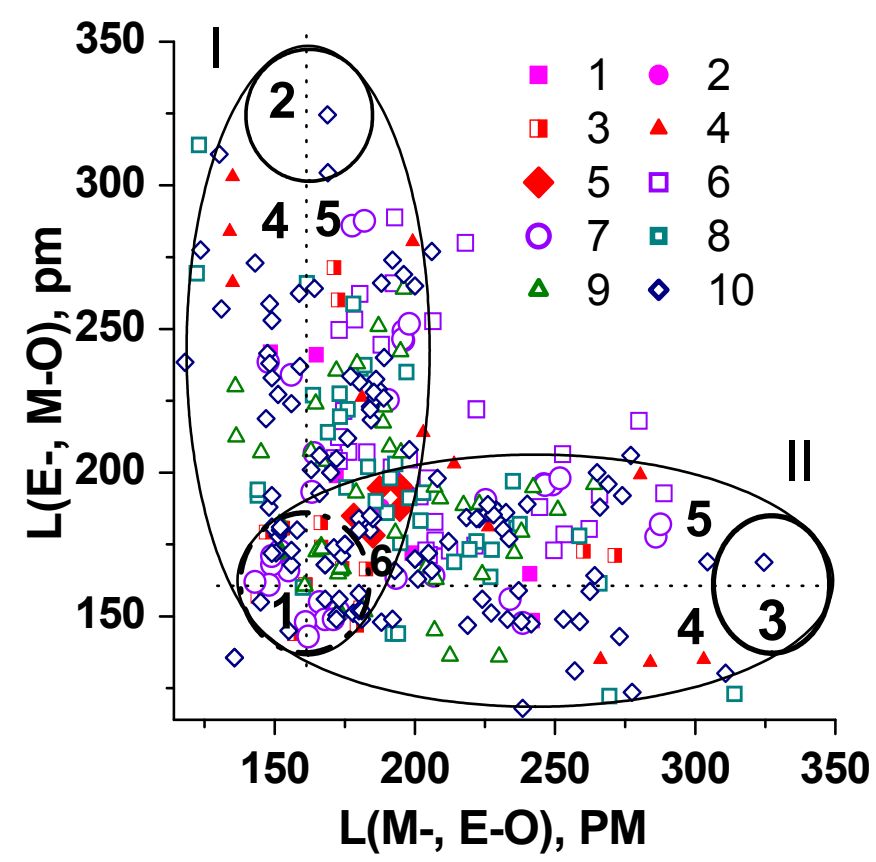

Figure 12. Ellipses of "acentricity" for the piezoelectric binary oxide crystals of affine group IV. Crystals with measurable acentric properties: $1-\mathrm{T} ; 2-\mathrm{D}_{6} ; 3-\mathrm{D}_{4} ; 4-\mathrm{D}_{3} ; 5-\mathrm{D}_{2}$. Crystals with nonmeasurable acentric properties: 6-T; 7- $\mathrm{D}_{6} ; 8-\mathrm{D}_{4} ; 9-\mathrm{D}_{3} ; 10-\mathrm{D}_{2}$.

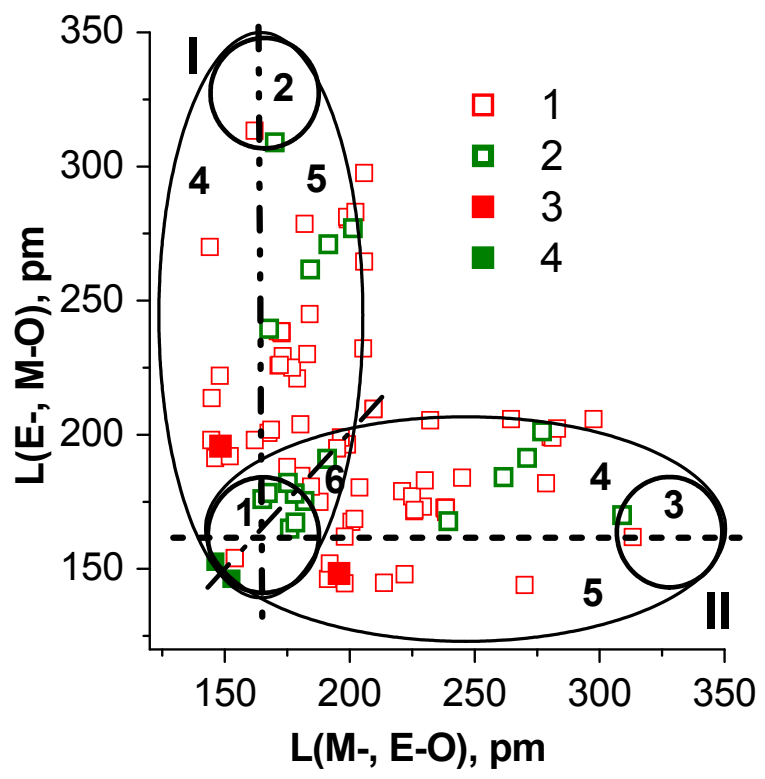

Figure 13. Ellipses of "acentricity" for the piezoelectric binary oxide crystals of affine group V. Crystals with nonmeasurable acentric properties: $1-\mathrm{D}_{2 \mathrm{~d}} ; 2-\mathrm{S}_{4}$. Crystals with measurable acentric properties: $3-\mathrm{D}_{2 \mathrm{~d}} ; 4-\mathrm{S}_{4}$. 


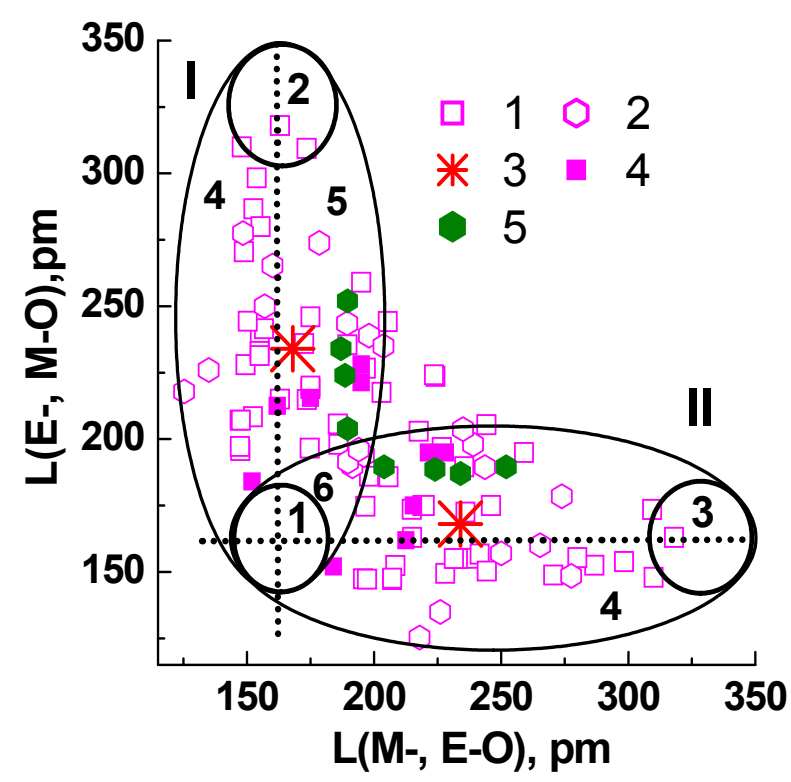

Figure 14. Ellipses of "acentricity" for the piezoelectric binary oxide crystals of affine group VI. Crystals with nonmeasurable acentric properties: $1-\mathrm{T}_{\mathrm{d}} ; 2-\mathrm{D}_{3 \mathrm{~h}} ; 3-\mathrm{C}_{3 \mathrm{~h}}$. Crystals with measurable acentric properties: $4-\mathrm{T}_{\mathrm{d}} ; 5-\mathrm{D}_{3 \mathrm{~h}}$.

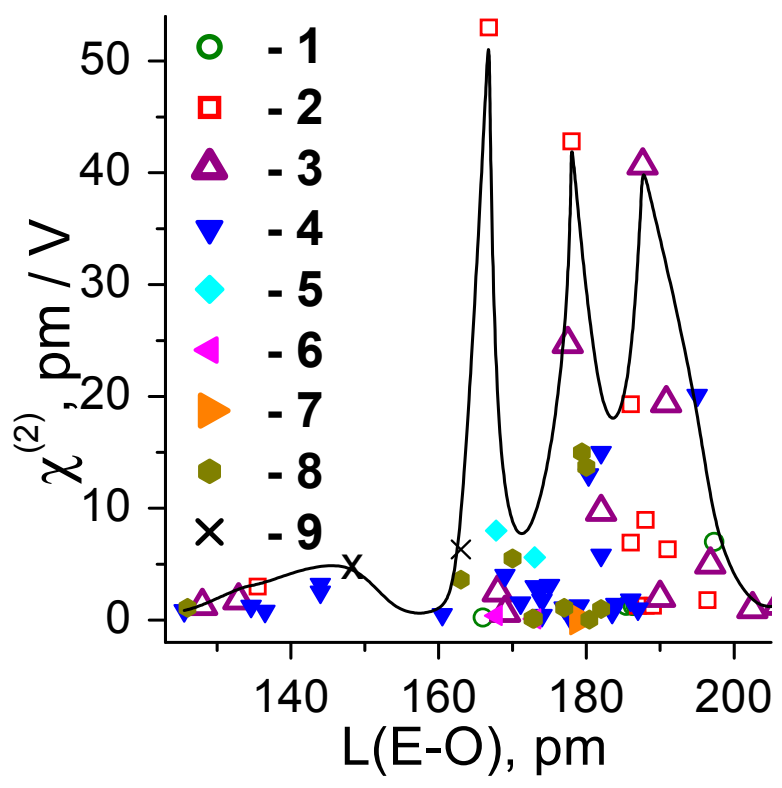

Figure 15. The fuzzy dependence of the upper envelope for function $\chi^{(2)}=\mathrm{f}(\mathrm{L}(\mathrm{E}-\mathrm{O})$ on the shortest oxide bond length of binary oxide crystals. Here: $1-\mathrm{C}_{6 \mathrm{v}}, 2-\mathrm{C}_{4 \mathrm{v}} ; 3-\mathrm{C}_{3 \mathrm{v}} ; 4-\mathrm{C}_{2 \mathrm{v}} ; 5-\mathrm{C}_{\mathrm{s}} ; 6-\mathrm{C}_{6} ; 7-\mathrm{C}_{3}, 8-\mathrm{C}_{2} ; 9-\mathrm{D}_{2 \mathrm{~d}}$.

Among crystals with $\pi$-oxide bonds, the sloping maximum of $\chi^{(2)}$ is observed for borate crystals $\left(\chi^{(2)}=6.3 \mathrm{pm} / \mathrm{v}, \gamma-\mathrm{LiBO}_{2}, \mathrm{D}_{2 \mathrm{~d}}, \mathrm{Li}_{2} \mathrm{~B}_{4} \mathrm{O}_{7}\left(\mathrm{C}_{4 \mathrm{v}}\right), \mathrm{BiB}_{3} \mathrm{O}_{6}\left(\mathrm{C}_{2}\right)\right.$, and $\left.\mathrm{PbB}_{4} \mathrm{O}_{7}\left(\mathrm{C}_{2 \mathrm{v}}\right), \chi^{(2)} \approx 3.2 \mathrm{pm} / \mathrm{V}\right)$. But the next sharp maximum is observed at $L(\mathrm{E}-\mathrm{O})=166 \mathrm{pm}$ for vanadite crystals $\left(\mathrm{PbVO}_{3}, \mathrm{C}_{4 \mathrm{v}}\right)$, at $L(\mathrm{E}-\mathrm{O})=180 \mathrm{pm}$-for niobate crystals $\left(\mathrm{LiNbO}_{3}, \mathrm{C}_{3 \mathrm{v}}\right)$ and at $L(\mathrm{E}-\mathrm{O})=188 \mathrm{pm}$ for the titanate crystals $\left(\mathrm{PbTiO}_{3}, \mathrm{C}_{4 \mathrm{v}}\right)$, having $\sigma$-oxide bonds.

So, according to the oxide bond length, the binary oxides are divided into three main taxa: (1) $\sim 120<\mathrm{L}(\mathrm{E}-\mathrm{O})<161 \mathrm{pm}$, acentric oxide crystals with $\pi$-oxide bonds; $(2) \sim 161<L(\mathrm{E}-\mathrm{O})<202 \mathrm{pm}$, 
acentric oxide crystals with $\sigma$-oxide bonds; (3) $L\left(\mathrm{M}_{1} / \mathrm{M}_{2}-\mathrm{O}\right)>202 \mathrm{pm}$, only centrosymmetric, nonpiezoelectric oxide crystals.

The similar fuzzy and nonmonotonous dependences of interrelation "sulfide (selenide) bond length-NLO susceptibility" are observed for piezoelectric sulfide (selenide) crystals $\left(\chi^{(2)}=\mathrm{f}(L(\mathrm{E}-\mathrm{S}))[41]\right.$ and also for telluride crystals [48].

Further, the more complex interrelation "composition-oxide bond length -structure-NLOsusceptibility" can be analyzed for the crystals of ternary oxide compounds: simple and binary borates and carbonates.

\section{Interrelationship "Composition-Structure-Oxide Bond Length-NLO Susceptibility" for Simple and Binary Borate Crystals}

Earlier, in our contributions, the key empiric interrelationship "composition-oxide bond length-structure" was particularly discussed for many binary and ternary oxide crystals: carbonates, borates, phosphates, silicates, germanates, vanadates, molybdates, wolframates, iodates, niobates, titanates, tantalates, zincates $[11,39,40,42,43,45,49-51,53-56]$. In reference book [6], $\beta-\mathrm{BaB}_{2} \mathrm{O}_{4}$, $\mathrm{LiB}_{3} \mathrm{O}_{5}, \mathrm{LiNbO}_{3}, \mathrm{KTiOPO}_{4}$ were mentioned among basic NLO crystals and among often-used NLO crystals- $\mathrm{KH}_{2} \mathrm{PO}_{4} . \mathrm{NH}_{4} \mathrm{H}_{2} \mathrm{PO}_{4}, \mathrm{KDPO}_{4}, \mathrm{CsLiB}_{6} \mathrm{O}_{10}, \mathrm{MgO}: \mathrm{LiNbO}_{3}, \mathrm{KTiOAsO}_{4}, \mathrm{KNbO}_{3}$, and among perspective crystals -8 simple and binary borates, and two fluoride borates. Besides, there are 9 borates among self-frequency-doubling laser crystals. For the last ten years, the number of new borate crystals has been appreciably increased, and many new borate-carbonate crystals have been grown [103-130]. Therefore, the key empiric interrelationship "oxide bond length-structure-nonlinear optical susceptibility" for simple and binary borate and carbonate crystals will be discussed further.

Besides moderate nonlinear optical (NLO) susceptibility $\chi^{(2)}$, acentric borate crystals are widely used in optoelectronics for the efficient optical frequency conversion in the visible and ultraviolet (UV) spectral ranges, and the creation of self-frequency-doubling lasers because of their high transparency and high optical damage threshold [4-6,14-19,56,66,67,103-130]. More 220 simple and binary acentric borate crystals, including new complex borate-carbonate, borate-nitrate, borate-acetate, hydroxyl-borate, borate-sulfate, borate-phosphate, borate-silicate, borate-fluoride, and other compounds with several different cations or anions [14-17,56,103-130] are currently known. Such crystals are also transparent in the UV range, and new borate-formate and borate-tartrate crystals can be synthesized in the nearest future.

Any materials must have a set of some definite properties to be used at the creation of optoelectronic devices. Therefore, a predictable list of the known and potential perspective crystals must be preliminarily compiled for selecting complex borate compounds and the crystals which are promising for high "acentric" and other properties. For this purpose, oxide bond lengths are a useful informative parameter of the main compound components. Consequently, the full data set of composition, structure and NLO susceptibility is compiled for borate crystals and presented in Table S2 (Supplementary information). Here, the chemical composition of binary borate crystals can be described by formulas $\mathrm{M}_{n} \mathrm{M}_{m} \mathrm{~B}_{\mathrm{p}} \mathrm{O}_{t}, \mathrm{M}_{\mathrm{n}} \mathrm{E}_{\mathrm{m}} \mathrm{B}_{\mathrm{p}} \mathrm{O}_{t}$, or $\mathrm{E}_{n} \mathrm{E}_{\mathrm{m}} \mathrm{B}_{\mathrm{p}} \mathrm{O}_{\mathrm{t}}$, where $\mathrm{B}-\mathrm{O}$ designates the bond "boron-oxygen", and cation types $\mathrm{E}$ and $\mathrm{M}$ are defined by the relation $\sim 120<L(\mathrm{E}-\mathrm{O}) \leq \sim 202 \mathrm{pm}<$ $L(\mathrm{M}-\mathrm{O})$. At computer plotting, the rosettes of three ellipses of acentricity are obtained on the plane of oxide bond lengths $L(E-O)-L(M-O)$ for piezoelectric binary oxide crystals, and formulas $\mathrm{M}_{m} \mathrm{M}_{n} \mathrm{~B}_{\mathrm{p}} \mathrm{O}_{\mathrm{t}}$, $\mathrm{M}_{m} E_{n} B_{p} O_{t}$ or $E_{m} E_{n} B_{p} O_{t}$ are also taken into account for the formation of a symmetric figure. These data include all 20 piezoelectric structures of complex borates, having both $\sigma-$ and $\pi$-oxide bonds (table). Two oxide bonds $L(\mathrm{M}-\mathrm{O})$, and $L(\mathrm{E}-\mathrm{O})$ are taken into account for plotting the "acentricity" ellipses of borate crystals.

Ii is seen that the set of the data on relation "oxide bond length-polar crystal structure" are positioned inside the vertical, horizontal and slope intersected ellipses of "acentricity" (I-III) (Figure 16). Here, the ellipse rosette contains also the intersecting part of two ellipses (I, II), or "onion", which is divided into a round part (circle 3) and a curvilinear triangle 
near the upper parts of the onion. The upper parts of ellipses are also designated by circles $4-5$, which are empty and do not contain binary borate crystals with the measurable acentric properties so far. The central part of ellipses I-II is divided into the left and right regions with subfields 1 and 2. The left part of ellipses I and the lower part of ellipses II in Figure 16 contain the crystals of borate-nitrites, borate-nitrates, borate-carbonates, borate-tartrates, borate-acetates, borate-formates, hydroxyl-borates, borate -sulfates and borate-phosphates with weak, moderate or average NLO-properties. The right part of ellipses I and the lower part of ellipses II in Figure 16 contain the crystals of borate-silicates, borate-selenates, borate-germanates, borate-vanadates, borate-arsenates, borate-molybdates, borate-wolframates, borate-iodates, borate-niobates, borate-titanates. borate-aluminates, borate-tantalates and borate-gallates. Besides, the subsidiary ellipses IV and V have been added for a more exact plotting of the ellipses set and the division of the field of NCS crystals by the ellipses axes, and by the borders into some characteristic regions and subfields (17) containing crystals with different structures and different $\chi^{(2)}$-levels: $\mathrm{M}_{n} \mathrm{M}_{m} \mathrm{~B}_{\mathrm{p}} \mathrm{O}_{t}$ (region 5-7), $\mathrm{M}_{n} \mathrm{E}_{\mathrm{m}} \mathrm{B}_{\mathrm{p}} \mathrm{O}_{t}$ (region 1-2), $\mathrm{E}_{n} \mathrm{E}_{\mathrm{m}} \mathrm{B}_{\mathrm{p}} \mathrm{O}_{t}$ (region 3). Region 7 is formed as a curvilinear rhomb and, in this region, the polar binary borate crystal $\mathrm{Pb}_{0.7} \mathrm{Ba}_{0.3} \mathrm{~B}_{4} \mathrm{O}_{7}$ has its maximum $\chi^{(2)}=5.1 \mathrm{pm} / \mathrm{V}$. In region 1 the $\mathrm{Pb}_{2}\left(\mathrm{BO}_{3}\right)\left(\mathrm{NO}_{3}\right)$ polar crystal $\left(\mathrm{C}_{6 \mathrm{v}}\right)$ has its maximal NLO susceptibility $\chi^{(2)}=2.4 \mathrm{pm} / \mathrm{V}$, while, in region 2, the $\mathrm{Ba}_{3} \mathrm{Ti}_{3} \mathrm{O}_{6}\left(\mathrm{BO}_{3}\right)_{2}$ nonpolar crystal has its maximum $\chi^{(2)}=28 \mathrm{pm} / \mathrm{V}\left(\mathrm{D}_{3 \mathrm{~h}}\right)$, the $\gamma-\mathrm{LiBO}_{2}$ crystal has $\chi^{(2)}=6.3 \mathrm{pm} / \mathrm{V}$ and for the $\mathrm{KNbB}_{2} \mathrm{O}_{6}$ crystal $\chi^{(2)}=6.1 \mathrm{pm} / \mathrm{V}$.

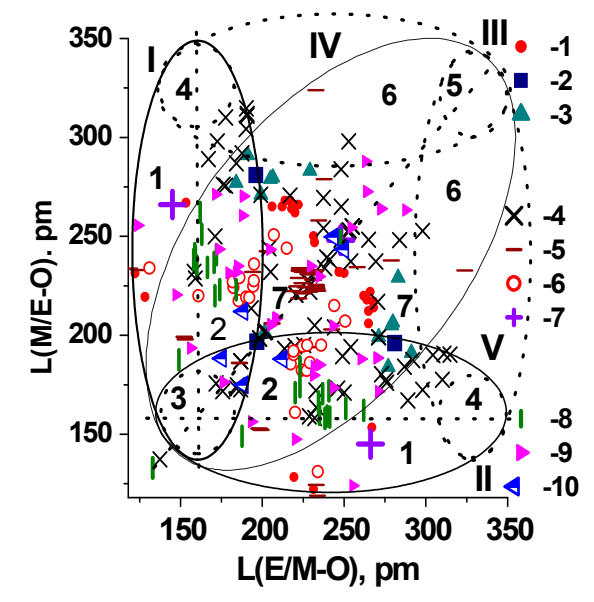

Figure 16. The set of simple and binary polar NLO-borate crystals on the coordinate plane of the shortest chemical bonds $\mathrm{L}(\mathrm{M}-\mathrm{O})$, and $\mathrm{L}(\mathrm{E}-\mathrm{O})$. Here: $1-\mathrm{C}_{6 \mathrm{v}}, 2-\mathrm{C}_{4 \mathrm{v}} ; 3-\mathrm{C}_{3 \mathrm{v}} ; 4-\mathrm{C}_{2 \mathrm{v}} ; 5-\mathrm{C}_{\mathrm{s}} ; 6-\mathrm{C}_{6} ; 7-\mathrm{C}_{4}, 8-\mathrm{C}_{3}$; $9-C_{2} ; 10-C_{1}$.

The same data set for the nonpolar borate crystals is presented in Figure 17, and three acentricity ellipses of I-III are also formed. It is evident now that this data set is not full, and some empty and incomplete regions (4-5) are observed along the ellipses edges in Figures 16 and 17. The simple borate crystals are positioned along the axis of ellipse III $\left(\mathrm{Li}_{2} \mathrm{~B}_{4} \mathrm{O}_{7}\left(\mathrm{C}_{4 \mathrm{v}}\right), \beta-\mathrm{BaB}_{2} \mathrm{O}_{4}\left(\mathrm{C}_{3 \mathrm{v}}\right), \mathrm{SrB}_{4} \mathrm{O}_{7}\left(\mathrm{C}_{2 \mathrm{v}}\right)\right.$, $\mathrm{PbB}_{4} \mathrm{O}_{7}\left(\mathrm{C}_{2 \mathrm{v}}\right), \mathrm{BiB}_{3} \mathrm{O}_{6}\left(\mathrm{PbB}_{2} \mathrm{O}_{7}\left(\mathrm{C}_{2 \mathrm{v}}\right)\right.$ (Figure 16). According to the data set in the table, the polar borate crystals have a higher level of NLO susceptibility $\left(0.1<\chi^{(2)}<6.1 \mathrm{pm} / \mathrm{V}\right)$ and they are positioned near and in the central regions of the ellipse rosette $(1,2,7)$. Besides, here two nonpolar crystals have the biggest values of $\chi^{(2)}:\left(\mathrm{Ba}_{3} \mathrm{Ti}_{3} \mathrm{O}_{6}\left(\mathrm{BO}_{3}\right)_{2}, \mathrm{D}_{3 \mathrm{~h}}, \chi^{(2)}=28 \mathrm{pm} / \mathrm{V}\right.$, lying inside region 2 , and $\gamma-\mathrm{LiBO}_{2}$, $\mathrm{D}_{2 \mathrm{~d}}, \chi^{(2)}=6.3 \mathrm{pm} / \mathrm{V}$ lying on the line of ellipses I and II intersection. But, other nonpolar crystals have a moderate and a low level of $\chi^{(2)}, 0<\chi^{(2)}<2.48 \mathrm{pm} / \mathrm{V}$ (Table S2, Supplementary Materials) $\left(\mathrm{Sr}_{2} \mathrm{Be}_{2} \mathrm{~B}_{2} \mathrm{O}_{7}, \mathrm{D}_{3 \mathrm{~h}} ; \mathrm{Cs}_{2} \mathrm{~B}_{4} \mathrm{SiO}_{9}, \mathrm{~S}_{4} ; \mathrm{CeSc}_{3}\left(\mathrm{BO}_{3}\right)_{4}, \mathrm{D}_{3} ; \mathrm{BiAlGa}_{2}(\mathrm{BO}) 4, \mathrm{D}_{3} ; \beta-\mathrm{RbB}_{3} \mathrm{O}_{5}, \mathrm{D}_{2} ; \mathrm{KMgBO}_{3}, \mathrm{~T}\right)$.

The interrelation "oxide bond length-NLO susceptibility" can be seen clearer from the function $\chi^{(2)}=\mathrm{f}[(\mathrm{B}-\mathrm{O})]$ for simple and binary borate crystals. This general fuzzy dependence of NLO 
susceptibility, $\chi^{(2)}$ on oxide bond length is presented in Figure 18. But, its upper envelope is nonmonotonous, and there are two clear maximum a at $L(\mathrm{~B}-\mathrm{O})=136$ and $148 \mathrm{pm}$. The very sharp maximum at $L(\mathrm{~B}-\mathrm{O})=136 \mathrm{pm}$ corresponds to the borate-titanate crystal, $\mathrm{Ba}_{3} \mathrm{Ti}_{3} \mathrm{O}_{6}\left(\mathrm{BO}_{3}\right)_{2}$ with $\sigma-\mathrm{Ti}-\mathrm{O}$ bonds, and several crystals are positioned at $L(\mathrm{~B}-\mathrm{O}) 133 / 138 \mathrm{pm}$ with the noticeable level of $\chi^{(2)}=4 / 6 \mathrm{pm} / \mathrm{V}$ (some of borate-niobates with the $\mathrm{C}_{2 \mathrm{v}}$ symmetry and $\mathrm{Bi}_{3} \mathrm{TeBO}_{9}, \mathrm{C}_{6}$ ).

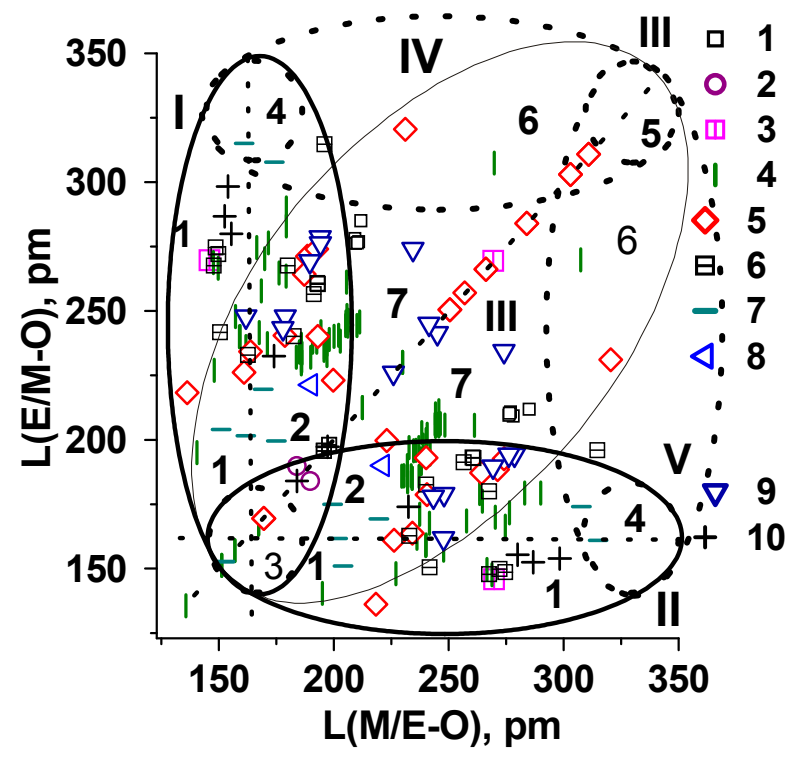

Figure 17. The set of simple and binary nonpolar NLO-borate crystals on the coordinate plane of the shortest chemical bonds L(M-O), and L(E-O). Here: 1-T; 2- $\mathrm{D}_{6} ; 3-\mathrm{D}_{4} ; 4-\mathrm{D}_{3} ; 5-\mathrm{D}_{2} ; 6-\mathrm{D}_{2 \mathrm{~d}} ; 7-\mathrm{S}_{4} ; 8-\mathrm{C}_{3 \mathrm{~h}}$, $9-\mathrm{D}_{3 \mathrm{~h}} ; 10-\mathrm{T}_{\mathrm{d}}$.

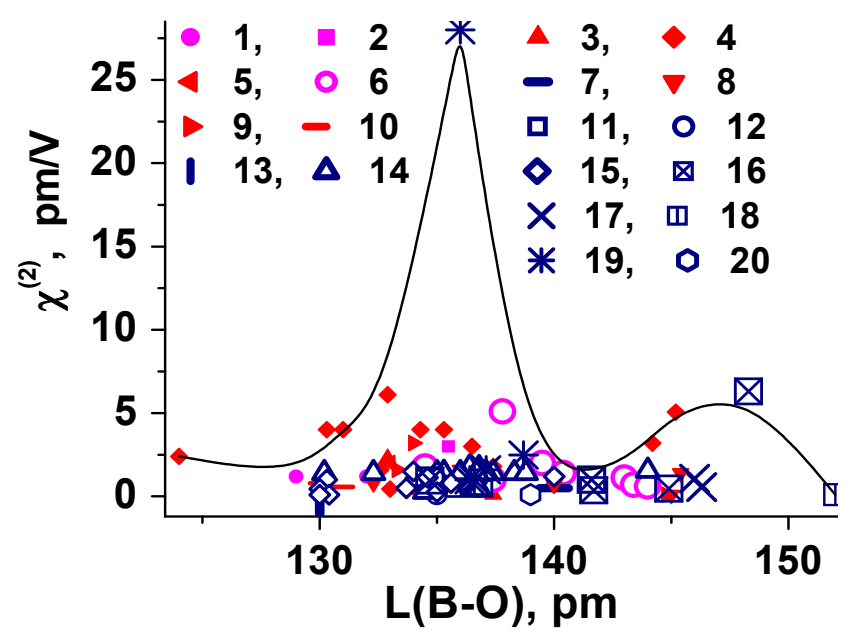

Figure 18. The fuzzy dependence of the ${ }^{(2)}=\mathrm{f}[(\mathrm{B}-\mathrm{O})]$ upper envelope on the shortest bond length. Dark: polar crystals $1-\mathrm{C}_{6 \mathrm{v}} ; 2-\mathrm{C}_{4 \mathrm{v}} ; 3-\mathrm{C}_{3 \mathrm{v}} ; 4-\mathrm{C}_{2 \mathrm{v}} ; 5-\mathrm{C}_{\mathrm{s}} ; 6-\mathrm{C}_{6} ; 7-\mathrm{C}_{4}, 8-\mathrm{C}_{3} ; 9-\mathrm{C}_{2} ; 10-\mathrm{C}_{1}$. Symbols 11-20-nonpolar crystals: $11-\mathrm{T} ; 12-\mathrm{D}_{6} ; 13-\mathrm{D}_{4} ; 14-\mathrm{D}_{3} ; 15-\mathrm{D}_{2} ; 16-\mathrm{D}_{2 \mathrm{~d}} ; 17-\mathrm{S}_{4}, 18-\mathrm{C}_{3 \mathrm{~h}}, 19-\mathrm{D}_{3 \mathrm{~h}} ; 20-\mathrm{T}_{\mathrm{d}}$.

So, the higher NLO susceptibility is predetermined by the high electronic polarizability of some transition metal ions $\left(\mathrm{Ti}^{4+}, \mathrm{Nb}^{5+}, \mathrm{Ta}^{5+}\right)$ contained by the oxygen ion in borate crystals $\left(\mathrm{CsNbOB}_{2} \mathrm{O}_{5}\right.$, $\left.\mathrm{TlNbB}_{2} \mathrm{O}_{6}, \mathrm{CsTaOB}_{2} \mathrm{O}_{5}\right)$. The second low-intensity maximum at $L(\mathrm{~B}-\mathrm{O}) 144-148 \mathrm{pm}$ is formed by $\gamma-\mathrm{LiBO}_{2}\left(\mathrm{D}_{2 \mathrm{~d}}, \chi^{(2)}=6.3 \mathrm{pm} / \mathrm{V}\right)$ and $\mathrm{Pb}_{0.7} \mathrm{Ba}_{0.3} \mathrm{~B}_{4} \mathrm{O}_{7}\left(\mathrm{C}_{2 \mathrm{v}}, \chi^{(2)}=5.1 \mathrm{pm} / \mathrm{V}\right)$ borate crystals. The marked difference of length $L(\mathrm{~B}-\mathrm{O})=124 \div 152 \mathrm{pm}$ is observed in borate crystals, and it is stipulated by 
the formation of many anionic borate groups: flat trigonal $\left(\mathrm{BO}_{3}\right)^{3-}$, tetragonal $\left(\mathrm{BO}_{4}\right)^{5-}$, ditrigonal $\left(\mathrm{B}_{2} \mathrm{O}_{5}\right)^{4-}$, ditetragonal $\left(\mathrm{B}_{2} \mathrm{O}_{7}\right)^{8-}$, flat ring-shaped $\left(\mathrm{B}_{3} \mathrm{O}_{6}\right)^{3-}$, the NLO susceptibility of which is different $[14-18,103,110,112]$. The same fuzzy dependence of $\chi^{(2)}$ on $L(\mathrm{M} / \mathrm{E}-\mathrm{O})$ for simple and binary borate crystals is presented in Figure 19. Three maxima at $L(E / M-O)=190,248$, and $298 \mathrm{pm}$ are observed here. The first maximum corresponds to the $\mathrm{Ba}_{3} \mathrm{Ti}_{3} \mathrm{O}_{6}\left(\mathrm{BO}_{3}\right)_{2}$ crystal, the second to the $\mathrm{Pb}_{0.7} \mathrm{Ba}_{0.3} \mathrm{~B}_{4} \mathrm{O}_{7}$ crystal and the third $\beta-\mathrm{RbB}_{3} \mathrm{O}_{5}\left(\mathrm{D}_{2}, \chi^{(2)}=1.5\right)$.

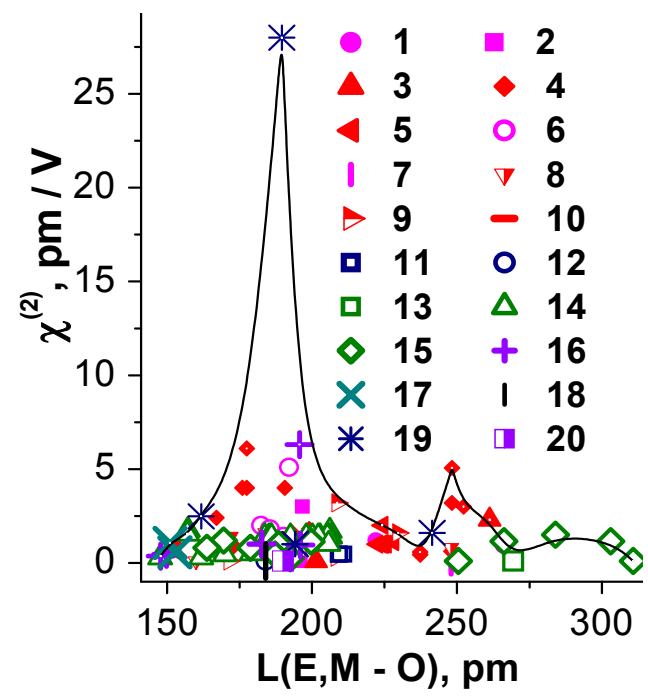

Figure 19. The fuzzy dependence of the $\chi^{(2)}=\mathrm{f}[(\mathrm{E}-\mathrm{O})]$ upper envelope on the shortest borate bond length, $L(\mathrm{M} / \mathrm{E}-\mathrm{O})$. Symbols $1-20$ are the same as in Figure 13.

So, the set of the shortest oxide bond lengths $L(\mathrm{M} / \mathrm{E}-\mathrm{O})$ is a key informative parameter for the systematization and search of new acentric oxide crystals for optoelectronics.

It is necessary to take into account all oxide bond lengths for the design of ternary oxides. In borate crystals, the oxide bond length $L(\mathrm{~B}-\mathrm{O})$ is equal to $124 \div 152 \mathrm{pm}$ and, potentially, these crystals may be "acentric". But, the oxide bond length $L(\mathrm{E}-\mathrm{O})$ must be in the interval $124<(L(\mathrm{E}-\mathrm{O}<202 \mathrm{pm}$ in ellipses I and II. The acentric ternary oxide crystals are divided into some groups (1-7), and they are positioned obligatorily in the ellipses of "acentricity I-III". Namely, the acentric binary borate crystals can be of three types: $M_{n} M_{m} B_{p} O_{t}, M_{n} E_{m} B_{p} O$, or $E_{n} E_{m} B_{p} O_{t}$. The fuzzy dependence of the NLO susceptibility on the oxide bond length is nonmonotonous, and the systematization of interrelationship "composition-structure-property" allows defining the perspective crystal composition (Figures 16-19) more precisely.

The structure of the first basic NLO borate crystal, $\beta-\mathrm{BaB}_{2} \mathrm{O}_{4}$, was precisely determined in 1984 as R3c [6,115]. Then the NLO properties were predicted by Ch. Chen and others [14,15], and the crystal growth technology was developed in many studies [117-119]. Earlier, and for the last years, some deep UV borate and fluoride-borate crystals have been grown [120-126]. These crystals expanded the possible boundary of transparence in the UV spectral region in comparison with borate crystals, and the essential part of these contributions was carried out by the Chen's group and other scientists $[14,15,101,120-130]$. The fluoride borate crystals $\mathrm{KBe}_{2} \mathrm{BO}_{3} \mathrm{~F}_{2}(\mathrm{KBBF}), \mathrm{RbBe}_{2} \mathrm{BO}_{3} \mathrm{~F}_{2}$ (RBBF), $\mathrm{CsBe}_{2} \mathrm{BO}_{3} \mathrm{~F}_{2}(\mathrm{CBBF})$ and $\mathrm{TlBe}_{2} \mathrm{BO}_{3} \mathrm{~F}_{2}$ (TBBF) have the trigonal $\mathrm{D}_{3}$-point symmetry (R32) [120-122]. The fluoride borate crystal, $\mathrm{Sr}_{3}\left[\left(\mathrm{Be}_{\mathrm{x}} \mathrm{B}_{1-\mathrm{x}}\right)_{3} \mathrm{O}_{10}\right]\left[\mathrm{Be}\left(\mathrm{O}_{1-\mathrm{x}} \mathrm{F}_{\mathrm{x}}\right)_{3}\right], \mathrm{x}=0.33$, has its polar trigonal $\mathrm{C}_{3 \mathrm{v}}$ point symmetry, while some other crystals $\left(\mathrm{BaAlBO}_{3} \mathrm{~F}_{2}, \mathrm{C}_{3 \mathrm{~h}}, \mathrm{Ba}_{7}\left(\mathrm{BO}_{3}\right)_{4-x} \mathrm{~F}_{2+3 x}, \mathrm{C}_{6}, \mathrm{Sr}_{2} \mathrm{Be}_{2} \mathrm{~B}_{2} \mathrm{O}_{7}, \mathrm{D}_{3 \mathrm{~h}}\right.$, $\mathrm{NaBeBO}_{3}, \mathrm{D}_{3 \mathrm{~h}}$ )-the hexagonal structure [124-128]. According to their oxide bond length, the borate and fluoride borate crystals with the moderate $\chi^{(2)}$-level are positioned in regions 1-2 or 7 (Figures 16 and 17). The theoretical DFT analysis, which was carried out last year, shows that $\mathrm{B}-\mathrm{O}$ groups have a 
dominant role in the SHG response, and F atoms serve as NLO active participants in the discussed fluoride borate crystals [130] (Supplementary Materials, (Table S2).

\section{Interrelationship "Composition-Structure-Oxide Bond Length-NLO Susceptibility" for Simple and Binary Carbonate Crystals}

For the last years, more intensive studies have been carried out in the search and synthesis of new carbon-containing oxide crystals, which are also of higher transparence in the UV spectral ranges [20-25,131-145] (carbonates [132,138,140,143,144], tartrates [133-135,145], formates [136], oxalates [137], acetates [109], and fluoride-carbonates [20-25]). These crystals also have their high optical damage threshold and the phase-matching angles in the UV spectral range. Besides, many complex carbon-oxide compounds with borates, hydroxides $[139,140]$, having both $\pi-$ and $\sigma$-oxide bonds, and also hydrogen $\mathrm{O}-\mathrm{H}$ bonds, including borate-carbonate, borate-acetate, borate-formate, borate-oxalate, borate-tartrate and other compounds with several different cations, or anions [109,133,137,139-142], are known. The search of such materials was carried out among fluorides, borates, carbonates and their derivatives. The most transparent crystals were found among fluorides, but only the $\mathrm{SbF}_{3}$ crystal has its moderate NLO susceptibility $\chi^{(2)}=1.93 \mathrm{pm} / \mathrm{V}$ [146], while the crystal of Rachel salt NaK tartrate $\chi^{(2)}=4.3 \mathrm{pm} / \mathrm{V}[6,12,27]$.

Further, the set of data on the composition, structure, oxide bond lengths, NLO susceptibility of carbon oxide crystals are compiled in table III (Supplementary Materials). The estimation of certain data on the oxide bond lengths is obtained on the ionic radii $[60,61]$, and NLO susceptibilities-from some reviews and reference books [60,61], including the $\chi^{(2)}$ measurements by the Kurtz and Perry method [65]. Besides, the $\chi^{(2)}$ values are correlated with other acentric properties: spontaneous polarization $\mathrm{P}_{\mathrm{s}}$, piezoelectric coefficient $\mathrm{d}$ and electro-optical coefficient $\mathrm{r}[12,13,57]$. The set of tabulated data embraces 18 crystalline piezoelectric structures with the exception of rare groups $C_{4 v}$ and $T_{d}$ [55].

The representation and plotting methods for correlations "composition-structure-property" are used the same as for borate crystals [56]. Each cation has one or several coordination polyhedrons in the oxide crystalline lattice, including 3-12 oxygen anions or a set of fluorine and oxygen anions in the fluoride-carbonate crystals [61]. Besides, the oxide (fluorine) bond lengths may be different inside each polyhedron [61]. But the strongest, shortest oxide bond length is conveniently used at a comparative crystal chemical analysis. This bond has one definite minimal length $L$ in each polyhedron. The data on 110 simple and complex carbon-oxide crystals, including the new fluoride-carbonate crystals having their high level of $\chi^{(2)}$, and all carbonate crystals having $\chi^{(2)} \geq 0.01 / 0.05 \mathrm{pm} / \mathrm{V}$, are presented in the table. Informative parameter $\mathrm{L}$ is a set of oxide bond lengths for carbon-oxide compounds with the chemical formulas $\mathrm{M}_{n} \mathrm{M}_{m} \mathrm{C}_{\mathrm{p}} \mathrm{O}_{t}, \mathrm{M}_{\mathrm{n}} \mathrm{E}_{\mathrm{m}} \mathrm{C}_{\mathrm{p}} \mathrm{O}_{\mathrm{t}}$, or $\mathrm{E}_{n} \mathrm{E}_{m} \mathrm{C}_{\mathrm{p}} \mathrm{O}_{\mathrm{t}}$, in which cations $\mathrm{E}$ and $\mathrm{M}$ correspond to inequalities $130 \mathrm{pm}<L(\mathrm{E}-\mathrm{O}) \leq 202 \mathrm{pm}<L(\mathrm{M}-\mathrm{O})$, and $115 \mathrm{pm} \leq L(\mathrm{C}-\mathrm{O}) \leq 155 \mathrm{pm}$.

It was shown in the sixth section for borate crystals that the existence of such inequality substantially defines the absence of an inversion center in the crystals and the level of NLO properties [56]. So, in Figure 20, the three partly intersected ellipses of "acentricity" I, II, III are plotted on the plane of oxide bonds $L(\mathrm{E}-\mathrm{O})-L(\mathrm{M}-\mathrm{O})$, in which the full set of the carbon-oxide compounds from the table is positioned. Here, the crystals of simple carbonates $\mathrm{M}_{n} \mathrm{C}_{\mathrm{p}} \mathrm{O}_{t}$ and $\mathrm{E}_{m} \mathrm{C}_{\mathrm{p}} \mathrm{O}_{t}$ are positioned on the long axis of slope ellipses III. The general picture is the same as it is observed for borate crystals [56].

The extreme dependence of function $\chi^{(2)}=\mathrm{F}(\mathrm{L}(\mathrm{CO}))$ is presented in Figure 21. Commonly, the level $\chi^{(2)}=0.05 / 2 \mathrm{pm} / \mathrm{V}$ is observed in the crystals of carbon-oxide compounds. Here, the low $\chi^{(2)}$ maximum at $\mathrm{L}(\mathrm{C}-\mathrm{O})$ 115-116 pm corresponds to the crystal of the Rachel (ferroelectric) salt, and the potassium tartrate NLO susceptibility is $\chi^{(2)}=4.2-4.3 \mathrm{pm} / \mathrm{V}$ [12]. But unexpectedly, a sharp and very high maximum $\chi^{(2)}$ at $\mathrm{L}(\mathrm{C}-\mathrm{O}) 128-129 \mathrm{pm}$ is observed for the crystals of potassium, rubidium and cesium fluorine-carbonates, in which the second cations are led, europium, or gadolinium (Supplementary Materials, Table S3, lines 64-65, 98, 105-106). 


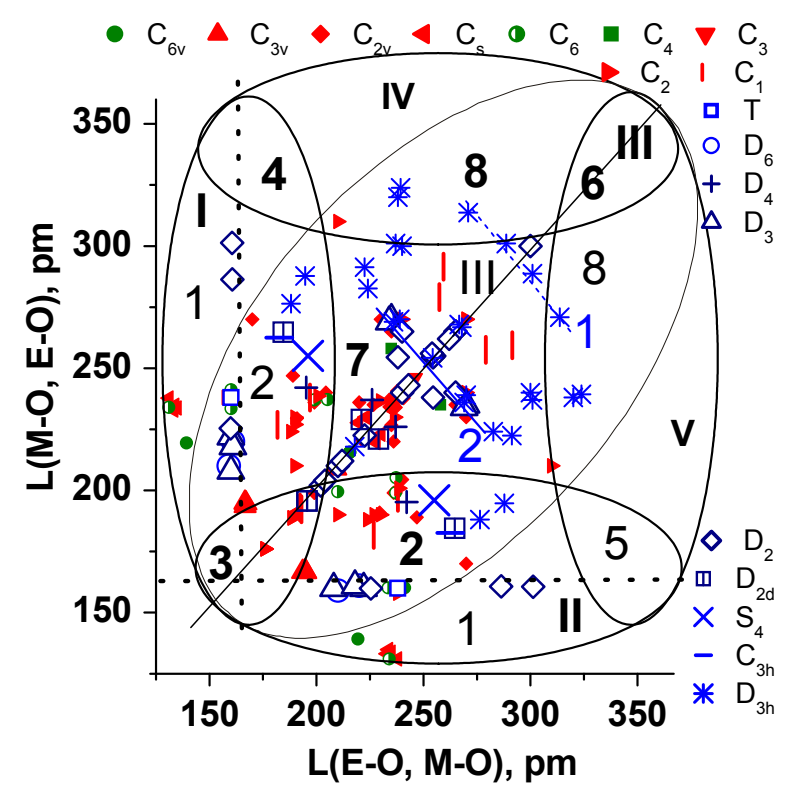

Figure 20. The set of the shortest oxide bond length for "acentric" simple and binary crystals of the carbon-oxide compounds. The point symmetry structure: $1-C_{6 v}, 2-C_{3 v}, 3-C_{2 v}, 4-C_{s}, 5-C_{6}, 6-C_{4}, 7-C_{3}$, $8-\mathrm{C}_{2}, 9-\mathrm{C}_{1}, 10-\mathrm{T}, 11-\mathrm{D}_{6}, 12-\mathrm{D}_{4}, 13-\mathrm{D}_{3}, 14-\mathrm{D}_{2}, 15-\mathrm{D}_{2 \mathrm{~d}}, 16-\mathrm{S}_{4}, 17-\mathrm{C}_{3 \mathrm{~h}}, 18-\mathrm{D}_{3 \mathrm{~h}}$.

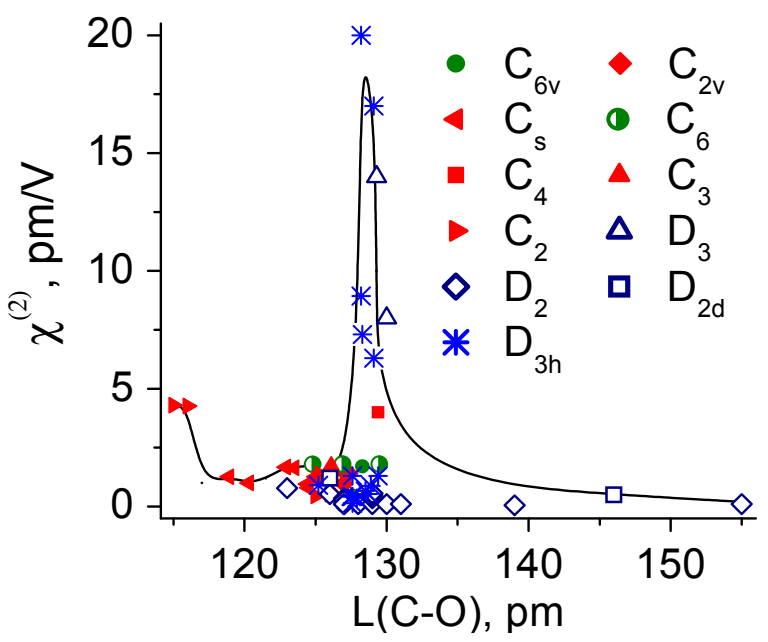

Figure 21. The empiric dependence of NLO susceptibility $\left(\chi^{(2)}\right)$ for the carbon-oxide crystals on the oxide bond length, $\mathrm{L}(\mathrm{C}-\mathrm{O})$. The point symmetry structure: $1-\mathrm{C}_{6 \mathrm{v}}, 2-\mathrm{C}_{2 \mathrm{v}}, 3-\mathrm{C}_{\mathrm{s}}, 4-\mathrm{C}_{6}, 5-\mathrm{C}_{4}, 6-\mathrm{C}_{3}, 7-\mathrm{C}_{2}$, $8-\mathrm{D}_{3}, 9-\mathrm{D}_{2}, 10-\mathrm{D}_{2 \mathrm{~d}}, 12-\mathrm{D}_{3 \mathrm{~h}}$.

So, the new crystals of the fluoride-carbonates have their high level $\chi^{(2)}=10-20 \mathrm{pm} / \mathrm{V}[20-22,129]$, while the crystals of fluoride-borate $\mathrm{BaAlBO}_{3} \mathrm{~F}_{2}$ have the value of $\chi^{(2)}$ only 1.1-1.5 pm/V [122]. This circumstance is stipulated by the increase of the "acentricity" degree in the coordination polyhedrons due to the existence of hetero-valence ligands, including $\mathrm{O}^{2-}$ and $\mathrm{F}^{-}$anions [128]. The crystals of fluoride-carbonates with the $\mathrm{D}_{3 \mathrm{~h}}$ structure are positioned on the plane of oxide bond lengths in the right part, near the boundary of slope ellipse III (Figure 20). In pure carbonate crystals, a low level of NLO susceptibility, less than $1.5 \mathrm{pm} / \mathrm{V}$, is observed, and a moderate level is observed to $\chi^{(2)}=2-4.3 \mathrm{pm} / \mathrm{V}$ for some tartrate crystals. These crystals are positioned in the central regions of the I-III ellipses. It is clearly seen that there are some empty regions in the upper and bottom parts of these ellipses, and some $\chi^{(2)}$ data are missing in the table. Nevertheless, such systematization and comparison of the 
interrelationship "composition-structure-property" among the carbon-oxide and borate NLO crystals are useful for a following search of new promising crystals in UV-optoelectronics.

So, the discovery of new high-efficiency NLO carbon-oxide crystals is required both as a theoretical explanation of new established facts at the creation of the technology and their perfect crystal growth. The thermal instability of fluorine-carbonates stimulates a further development of low hydrothermal crystal growth methods, and the corrosion-proof autoclaves. Besides, a systematical search and synthesis of new complex compounds, forming the UV transparence NLO crystals, is necessary.

\section{Discussion and Conclusions}

The prediction, crystal growth, investigation of many properties and the application of new piezoelectric borate crystals in optoelectronics are the outstanding events in the development of solid state physics and solid state chemistry. Many solid state devices in modern nonlinear optics, acoustic-electronics and optoelectronics are impossible without these advanced materials. The creation of new perfect borate crystals is also impossible without an essential development of crystal growth methods and further investigation of physical chemistry of multicomponent borate melts, glasses, solutions, and crystals [147,148].

The use of new piezoelectric oxide crystals for the creation of different optoelectronic devices is predetermined by their complex of high physical properties and NCS-structures [2-6,27-33]. For example, the creation of a new thermo-stable sensor, and SAW devices is possible now using new ternary oxide crystals with the "langasite" structure, $\mathrm{D}_{3}\left(\mathrm{La}_{3} \mathrm{Ga}_{5} \mathrm{SiO}_{14}, \mathrm{La}_{3} \mathrm{TiGa}_{5} \mathrm{O}_{14}, \mathrm{La}_{3} \mathrm{Ga}_{5.5} \mathrm{Nb}_{0.5} \mathrm{O}_{14}\right.$, $\mathrm{Ca}_{3} \mathrm{TaGa}_{3} \mathrm{Si}_{2} \mathrm{O}_{14}$, and others), and also the crystals of binary borates, $\mathrm{C}_{\mathrm{s}}\left(\mathrm{LnCa}_{4} \mathrm{O}\left(\mathrm{BO}_{3}\right)_{3}, \mathrm{Ln}=\mathrm{Ln}, \mathrm{Y}\right.$, $\mathrm{Sm}, \mathrm{Tb}, \mathrm{Lu})[2,3,30-32,66,67,149]$. The new acentric crystal zinc metaborate is also thermo-stable [100]. It can be noted that many oxide piezoelectric crystals with high NLO-susceptibility $\left(\chi^{(2)}>30 \mathrm{pm} / \mathrm{V}\right.$, Figure 5) have a low optical damage threshold, and they cannot be useful in optoelectronics [2]. The primary use of simple, binary and multi-component borate crystals in nonlinear optics must be extended also by the creation of new self-frequency doubling lasers and new hard materials.

Therefore, the comparison of acentric properties of piezoelectric oxide crystals is very helpful for applied physics. But the fuzzy character of many empiric interrelations is needed in large statistics of experimental data on crystal properties [38-58].

Besides, it can be noted that, despite the fuzzy character of interrelation "composition-structure property" for the NCS oxide crystals, the knowledge of the upper boundary of dependence NLO susceptibility-oxide bond length is very useful for the general search and design of new NLO materials having the necessary complex of physical properties [45]. Particularly, the interrelation "pseudosymmetry-nonlinear optical property" has been studied in more detail for the last years for the series of simple NCS compounds and more complex ternary oxide compounds in the classes of potassium titanyl phosphate crystals [150-152].

For the last years, the formation of the acentric enanthiomorphic crystals of 20 aminoacids from natural aqueous solutions has been studied in some contributions [153]. Consequently, the systemic study and the knowledge of interrelationship "composition-structure-acentric property" of a more complete set of simple, binary and multicomponent oxide crystals is a key indicator for the fundamental understanding of the significance of acentric crystal structure and the optical activity in the natural processes of life origin $[154,155]$.

Supplementary Materials: The following are available online at www.mdpi.com/2073-4352/7/4/109/s1, Table S1: Real binary acentric binary oxide (polar piezoelectric).

Acknowledgments: The author acknowledges Vladimir K. Makukha, and Victor V. Atuchin for their longtime collaboration and the essential contribution to our joint papers.

Conflicts of Interest: The authors declare no conflict of interest. 


\section{References}

1. Gorelik, S.S. Again about the understanding of the notion "material science" and "material". Mater. Electron. Technol. 2006, 2, 25-28. (In Russian)

2. Rez, I.S.; Poplavko, Y.M. Dielectrics. Main Properties and Applications; Radio and Svyaz': Moscow, Russia, 1989; p. 288. (In Russian)

3. Jones, D.J.; Prasad, S.E. Wallace, J.B. Piezoelectric materials and their applications. Key Eng. Mater. 1996, 122, 71-143. [CrossRef]

4. Kaminskii, A.A. Crystalline Lasers: Physical Processes and Operating Schemes; CRC Press: Boca Raton, FL, USA, 1996.

5. Brenier, A. The self-doubling and summing lasers: Overview and modelling. J. Lumin. 2000, 91, 121-132. [CrossRef]

6. Nikogosyan, D.N. Nonlinear Optical Crystals: A Complete Survey; Springer: New York, NY, USA, $2005 ;$ p. 427.

7. Nowacki, W. Crystal Data; American Crystallographic Association: Buffulo, NY, USA, 1967.

8. Arkhipenko, D.K.; Moroz, T.N. Refinement of the space group of the mineral based on analysis of vibration spectra selection rules. Crystallographiya 1996, 41, 975-978. (In Russian)

9. Strunz, H. Mineralogische Tabellen; Akademische Verlaksgesselschaft Geest\&Porting K.G.: Leipzig, Germany, 1957.

10. Halasyamani, P.S.; Poeppelmeier, K.R. Nonventrosymmetric oxides. Chem. Mater. 1998, 10, $2753-2769$. [CrossRef]

11. Kidyarov, B.I.; Atuchin, V.V.; Pervukhina, N.V. Crystal structure-property relationship as a factor in the refinement of structural physical data. J. Struct. Chem. 2010, 51, 1119-1125. [CrossRef]

12. Iona, F.; Shirane, D. Ferroelectric crystals. M. Mir. 1965, 555, 168.

13. Lines, M.T.; Glass, M.L. Properties and Application of Ferroelectrics and Related Materials; Clarendon Press: Oxford, UK, 1977; p. 500.

14. Chen, Ch.; Liu, G. Recent advances in nonlinear optical and electro-optical materials. Ann. Rev. Mater. Sci. 1986, 16, 203-243. [CrossRef]

15. Chen, C.; Wu, Y.; Li, R. The anionic group theory of the nonlinear optical effect and its application in the development of new high quality NLO crystals in the borate series. Int. Rev. Phys. Chem. 1989, 8, 69-91. [CrossRef]

16. Chen, C.; Ye, N.; Wu, B.; Zeng, W.; Chen, Q.; Zhang, Y. Design and Synthesis of New Nonlinear Optical Crystals. In Proceedings of the International Symposium on Laser and Nonlinear Optical Materials; Sasaki, T., Ed.; Data Storage Institute: Singapore, 1997; pp. 103-119.

17. Chen, C.; Sasaki, T.; Li, R.; Wu, Z.; Lin, Z.; Mori, Y.; Hu, Z.; Wang, J.; Uda, S.; Yoshimura, M.; et al. Nonlinear Optical Borate Crystals, Principles and Applications; Wiley-VCH Verlag GmbH \& Co. KGaA: Weinheim, Germany, 2012; p. 387.

18. Jiang, X.; Luo, S.; Kang, L.; Gong, P.; Huang, H.; Wang, S.; Lin, Z.; Chen, C. First-Principles Evaluation of the Alkali and/or Alkaline Earth Beryllium Borates in Deep Ultraviolet Nonlinear Optical Applications. ACS Photon. 2015, 2, 1183-1191. [CrossRef]

19. Tran, T.T.; Yu, H.; Rondinelli, J.M.; Poeppelmeier, K.R.; Halasyamani, P.S. Deep Ultraviolet Nonlinear Optical Materials. Chem. Mater. 2016, 28, 5238-5258. [CrossRef]

20. Zou, G.; Huang, L.; Ye, N.; Lin, C.; Cheng, W.; Huang, H. CsPbCO 3 F: A Strong Second-Harmonic Generation Material Derived from Enhancement via $\mathrm{p}-\pi$ Interaction. J. Am. Chem. Soc. 2013, 135, 18560-18566. [CrossRef] [PubMed]

21. Tran, T.T.; Halasyamani, P.S. New fluoride carbonates: Centrosymmetric $\mathrm{KPb}_{2}\left(\mathrm{CO}_{3}\right)_{2} \mathrm{~F}$ and non-centrosymmetric $\mathrm{K}_{2.70} \mathrm{~Pb}_{5.15}\left(\mathrm{CO}_{3}\right)_{5} \mathrm{~F}_{3}$. Inorg. Chem. 2013, 52, 2466-2473. [CrossRef] [PubMed]

22. Tran, T.T.; Halasyamani, P.S.; Rondinelli, J.M. Role of Acentric Displacements on the Crystal Structure and Second-Harmonic Generating Properties of $\mathrm{RbPbCO} 3 \mathrm{~F}$ and $\mathrm{CsPbCO}_{3} \mathrm{~F}$. Inorg. Chem. 2014, 53, 6241-6251. [CrossRef] [PubMed]

23. Yang, G.; Peng, G.; Ye, N.; Wang, J.; Luo, M.; Yan, T.; Zhou, Y. Structural Modulation of Anionic Group Architectures by Cations to Optimize SHG Effects: A Facile Route to New NLO Materials in the ATCO3F $(\mathrm{A}=\mathrm{K}, \mathrm{Rb} ; \mathrm{T}=\mathrm{Zn}, \mathrm{Cd})$ Series. Chem. Mater. 2015, 27, 7520-7530. [CrossRef] 
24. Zou, G.; Nam, G.; Kim, H.G.; Jo, H.; You, T.S.; OK, K.M. ACdCO(3)F (A = K and Rb): New noncentrosymmetric materials with remarkably strong second-harmonic generation (SHG) responses enhanced via pi-interaction. RSC Adv. 2015, 5, 84754-84761. [CrossRef]

25. Zou, G.; Ye, N.; Huang, L.; Lin, X.S. Alkaline-Alkaline Earth Fluoride Carbonate Crystals ABCO(3)F (A = K, $\mathrm{Rb}, \mathrm{Cs} ; \mathrm{B}=\mathrm{Ca}, \mathrm{Sr}, \mathrm{Ba}$ ) as Nonlinear Optical Materials. J. Am. Chem. Soc. 2011, 133, 2001-2007. [CrossRef] [PubMed]

26. Reference Book on Lasers; Prokhorov, A.M., Sovetskoe, M., Eds.; Sovetskoe Radio: Moscow, Russia, 1978; pp. 237-330. (In Russian)

27. Kuz'minov, Y.S. Ferroelectric Crystals for Conversion of the Laser Radiation; Nauka: Moscow, Russia, $1982 ;$ p. 400. (In Russian)

28. Prokhorov, A.V.; Kuz'minov, Y. Physics and Chemistry of Crystalline Lithium Niobate; dam Kluver. Bristol.: Bristol, ME, USA, 1990.

29. Blistanov, A.A.; Bondarenko, V.S.; Perelomova, N.V.; Strizhevskaya, F.N.; Tchkalova, V.V.; Shaskolskaya, M.P. Acoustic Crystals, Reference Book; Nauka: Moscow, Russia, 1982; p. 632. (In Russian)

30. Tressler, J.F.; Alkoy, S.; Newnham, R.E. Piezoelectric sensors and sensor materials. J. Electroceram. 1998, 2, 257-272. [CrossRef]

31. Baettig, P.; Schelle, C.F.; LeSar, R.; Waghmare, U.V.; Spaldin, N.A. Theoretical prediction of new high-performance lead-free piezoelectrics. Chem. Mater. 2005, 17, 1376-1380. [CrossRef]

32. Advanced Piezoelectric Materials. Science, and Technology; Uchino, K., Ed.; Woodhead Publishing Limited: Cambridge, UK, 2010.

33. Chen, X.; Deng, H.; Zhang, H.; Lin, D.; Zhao, X.; Luo, H. The growth and properties of lead free ferroelectrics single crystals. Crystals 2015, 5, 172-192.

34. Shen, C.; Zhang, S.; Cao, W.; Cong, H.; Yu, H.; Wang, J.; Zhang, H. Thermal and electromechanical properties of melilite-type piezoelectric single crystals. J. Appl. Phys. 2015, 117, 064106. [CrossRef]

35. Moure, C.; Peňa, O. Races Advances in Perovskites: Processing and Properties. Progr. Solid State Chem. 2015, 43, 123-148. [CrossRef]

36. Cooper, R.V.; Voas, B.K.; Bridges, C.A.; Morris, J.R.; Beckman, S.P. First principles materials design of novel functional oxides. J. Adv. Dielectr. 2016, 6, 165001. [CrossRef]

37. Kidyarov, B.I.; Atuchin, V.V. Universal crystal classification system "point symmetry-physical property". Ferroelectrics 2007, 360, 96-99. [CrossRef]

38. Atuchin, V.V.; Kidyarov, B.I.; Pervukhina, N.V. Phenomenological modeling and design of new acentric crystal for optoelectronics. Comput. Mater. Sci. 2004, 30, 411-418. [CrossRef]

39. Atuchin, V.V.; Kidyarov, B.I.; Pervukhina, N.V. Shortest chemical bond length as a criteria for searching new noncentrosymmetric phosphate crystals. Ceram. Int. 2004, 30, 2005-2009. [CrossRef]

40. Atuchin, V.V.; Kidyarov, B.I.; Pervukhina, N.V. Shortest chemical bond lengths as a criteria for search new noncentrosymetric niobate and tantalate crystals with high optical nonlinearity. J. Cryst. Growth 2005, 275, e1941-e1946. [CrossRef]

41. Atuchin, V.V.; Kidyarov, B.I.; Pervukhina, N.V. Systematics and design of noncentrosymmetric sulphides and selenides for nonlinear optics. Comput. Mater. Sci. 2006, 32, 507-511. [CrossRef]

42. Atuchin, V.V.; Kidyarov, B.I.; Pervukhina, N.V. Systematization and interrelationship of micro-, and macrostructure with physical properties of oxide crystals without inversion centre. II. Nonlinear property of binary oxide crystals. Nano-Micro-Syst. Technol. 2006, 5, 20-25. (In Russian)

43. Kidyarov, B.I.; Atuchin, V.V. Interrelationship of micro-and macro-structure with physical properties of binary acentric oxide ferroelactic and paraelastic crystals. Ferroelectrics 2007, 360, 104-110. [CrossRef]

44. Atuchin, V.V.; Kidyarov, B.I.; Tsirkina, N.L. Classification of Noncentrosymmetric Oxides with Re ${ }^{3+}$ Ions Applicable for Self Frequency Doubling (SFD) Laser Crystals. In Proceedings of the SPIE International Conference on Nonlinear Optics, ICONO/LAT-2006, St. Petersburg, Russia, 25-30 June 2006; p. 6610w.

45. Kidyarov, B.I.; Atuchin, V.V.; Pervukhina, N.V. Interrelation of the macrostructure and microstructure with the nonlinear optical properties of iodate and titanate crystals. Phys. Solid State 2009, 51, 1548-1552. [CrossRef]

46. Kidyarov, B.I.; Atuchin, V.V. The simple and binary fluorides. Interrelationship "structure-nonlinear optical property" for halogenide crystals. Izvestiya Vuzov. Physics 2009, 3, 158-163. 
47. Atuchin, V.V.; Kidyarov, B.I.; Makukha, V.K. Interrelationship “Structure-Nonlinear Optical Properties" for Simple and Binary Acentric Chlorides. In Proceedings of the International Forum on Strategic Technologies, Ho Chi Minh City, Vietnam, 21-23 October 2009; Ho Chi Minh City Publishing House: Vietnam National University, Vietnam, 2009; pp. 162-164.

48. Atuchin, V.V.; Kidyarov, B.I.; Makukha, V.K. Classification of Binary Acentric Tellurides. In Proceedings of the International Forum on Strategic Technologies, Ho Chi Minh City, Vietnam, 21-23 October 2009; Ho Chi Minh City Publishing House: Vietnam National University, Vietnam, 2009; pp. 58-60.

49. Kidyarov, B.I.; Atuchin, V.V. Systematization of simple and binary silicates according to relationship "composition -structure-property". Ferroelectrics 2010, 397, 169-176. [CrossRef]

50. Kidyarov, B.I.; Atuchin, V.V. Interrelationship "composition-structure-nonlinear optical properties" in aluminate crystals. Ferroelectrics 2010, 397, 151-158. [CrossRef]

51. Kidyarov, B.I.; Atuchin, V.V. Interrelationship of micro-and macrostructure with nonlinear optical properties of simple and binary acentric niobate crystals. Ferroelectrics 2010, 397, 159-168. [CrossRef]

52. Zhang, L.; Atuchin, V.; Kidyarov, B.; Andreev, Y. Taxonomy, Chemical Bonding Relations, and Nonlinear Optical Properties of Noncentrosymmetric Sulfide Crystals. In Proceedings of the 2nd International Symposium on Laser Interaction with Matter (LIMIS 2012), Xi'an, China, 9 September 2013; Liu, J., Cao, J., Kaierle, S., Eds.; 2013; Volume 8796-2A.

53. Kidyarov, B.I.; Atuchin, V.V. Interrelationship "Structure-Property" for the Crystals of Noncentrosymmetric Tungstates. Ferroelectrics 2013, 444, 144-149. [CrossRef]

54. Kidyarov, B.I.; Atuchin, V.V.; Troitskaia, I.B. Interrelationship of micro-and macrostructure with physical properties of germanates. Ferroelectrics 2013, 444, 137-143.

55. Kidyarov, B.I.; Makukha, V.K. Interrelationship of the Structural and Nonlinear-Optical Properties of the Carbonate Crystals. In Proceedings of the 13th International Scientific-Technical Conference on Actual Problems of Electronics Instrument Engineering (APEIE) (APEIE-2016), Novosibirsk, Russia, 5-6 October 2016; Volume 12, pp. 390-394.

56. Kidyarov, B.I.; Makukha, V.K. Structural and Physical Systematization of the Nonlinear-Optical Borate Crystals. In Proceedings of the IFOST-2016, 11th International Forum on Strategic Technology (IFOST), Novosibirsk, Russia, 1-3 June 2016; Novosibirsk State Technical University Russia: Novosibirsk, Russia, 2016; pp. 539-543.

57. Kidyarov, B.I.; Makukha, V.K. Comparison of the Acentric Properties for the Oxide Crystals. In Proceedings of the 12th International Conference on Actual Problems of Electronics Instrument Engineering (APEIE)-34006, Novosibirsk, Russia, 2-4 October 2014; Volume 7, pp. 61-63.

58. Kidyarov, B.I.; Makukha, V.K. Interrelationship "structure-hardness-fusibility" for oxide crystals. In Proceedings of the 12th International Conference on Actual Problems of Electronics Instrument Engineering (APEIE)-34006, Novosibirsk, Russia, 2-4 October 2014; Volume 7, pp. 64-67.

59. Katritzky, A.R.; Kuanar, M.; Slavov, S. Quantitative Correlation of Physical and Chemical Properties with Chemical Structure: Utility for Prediction. Chem. Rev. 2010, 110, 5714-5789. [CrossRef] [PubMed]

60. Shanon, R.D. Revised effective ionic radii and systematic studies of interatomic distances in halides and chalkogenides. Acta Cryst. 1976, A32, 751-760. [CrossRef]

61. Urusov, V.S. Theoretical Crystal-Chemistry; Moscow State University: Moscow, Russia, 1987; p. 275.

62. Sirotin, Y.I.; Shaskolskaya, M.P. Fundamentals of Crystal Physics; Mir Publishers: Moscow, Russia, $1982 ;$ p. 680.

63. Aizu, K. Possible species of "ferroelastic" crystals and of simultaneously ferroelectric and ferroelastic crystals. J. Phys. Soc. Jpn. 1969, 27, 387-396. [CrossRef]

64. Rapoport, I.N. Electrooptic Effect on the Quadratic, and Cubic Nonlinearity. Ph.D. Thesis, Fare East State University for Means of Communication, Khabarovsk, Russia, 2000; p. 18.

65. Kurtz, S.K.; Perry, T.T. A powder technique for evaluation of nonlinear optical materials. J. Appl. Phys. 1968, 39, 3798-3813. [CrossRef]

66. Zhang, S.; Cheng, Z.; Lu, J.; Li, G.; Lu, J.; Shao, Z.; Chen, H. Studies on the effective nonlinear coefficient of $\mathrm{GdCa}_{4} \mathrm{O}\left(\mathrm{BO}_{3}\right)_{3}$ crystal. J. Cryst. Growth 1999, 205, 453-456. [CrossRef]

67. Aka, G.; Mougel, F.; Augé, F.; Kahn-Harari, A.; Vivien, D.; Bénitez, J.M.; Salin, F.; Pelenc, D.; Balembois, F.; Georges, P.; et al. Overview of the laser and non-linear optical properties of calcium-gadolinium-oxo-borate $\mathrm{Ca}_{4} \mathrm{GdO}\left(\mathrm{BO}_{3}\right)_{3}$. J. Alloys Compd. 2000, 303-304, 401-408. [CrossRef] 
68. Belik, A.A.; Azuma, M.; Saito, T.; Shimakawa, Y.B. Crystallographic features, and tetragonal phase stability of $\mathrm{PbVO}_{3}$, a new member of $\mathrm{PbTiO}_{3}$ family. Chem. Mater. 2005, 17, 269-273. [CrossRef]

69. Fukuda, T. Growth and crystallographic characteristic of $\mathrm{K}_{3} \mathrm{Li}_{2} \mathrm{Nb}_{5} \mathrm{O}_{15}$ single crystals. Jpn. J. Appl. Phys. 1969, 8, 122-126. [CrossRef]

70. Adachi, M.; Kawabata, A. Elastic and piezoelectric properties of potassium lithium niobate (KLN) crystals. Jpn. J. Appl. Phys. 1978, 17, 1969-1973. [CrossRef]

71. Xu, J.; Fan, S.; Xu, X. Bridgment growth and properties of potassium lithium niobate crystals. Progr. Cryst. Growth Character. Mater. 2000, 40, 137-144.

72. Huang, L.Z.; Zhao, K.Y.; Ruan, W.; Ruan, X.Z.; Zhao, W.; Zeng, J.T.; Li, G.R. Enhancement of Piezoelectric Properties of PMN-PT Based Ceramics in Low Temperatures. Abstracts Book. In Proceedings of the 11th Russia-CIS-Baltic-Japan Symposium on Ferroelectricity, Ekaterinburg, Russia, 20-24 August 2012; Ural Federal University: Ekaterinburg, Russia, 2012; p. 74.

73. Fang, B.J.; Ding, C.L.; Wu, J. Preparation of $\mathrm{Pb}(\mathrm{Mg} 1 / 3 \mathrm{Nb} 2 / 3) \mathrm{O}-3-\mathrm{PbTiO} 3$ ceramics by reaction-sintering method and their electrical properties. Eur. Phys. J. Appl. Phys. 2012, 57, 30101. [CrossRef]

74. Srimathy, B.; Jayavel, R.; Ganesamoorthy, S. Crystal growth of PZN-PT single crystals and critical issues for higher piezoelectric coefficient. Cryst. Res. Technol. 2012, 47, 523-529. [CrossRef]

75. Shvartsman, V.V.; Lupascu, D.C. Lead-Free Relaxor Ferroelectrics. J. Am. Ceram. Soc. 2012, 95, 1-26. [CrossRef]

76. Inaguma, Y.; Aimi, A.; Shirako, Yu.; Sakurai, D.; Mori, D.; Kojitani, H.; Akaogi, M.; Nakayama, M. High pressure synthesis, crystal structure and phase stability relations of a $\mathrm{LiNbO}_{3}$ type polar titanate $\mathrm{ZnTiO}_{3}$ and its reinforced polarity by the second-order Jahn-Teller effect. J. Am. Chem. Soc. 2014, 136, 2748-2756. [CrossRef] [PubMed]

77. Tian, J.; Han, P. Growth and Characterization on PMN-PT-Based Single Crystals. Crystals 2014, 4, 331-341. [CrossRef]

78. Fourquet, L.; Le Bail, A.; Gillet, P.A. LiNbWO 6 : Crystal structure of its two allotropic forms. Mater. Res. Bull. 1988, 23, 1163-1170. [CrossRef]

79. Wiegel, M.; Blasse, G.; Ouwerkerk, M. Bond-orbital calculations of the non-linear optical response of lithium niobate-related compounds. J. Phys. Condens. Matter. 1995, 7, 675-683. [CrossRef]

80. Eun, C.O.; Alberto, G.; Min, O.K.; Lei, Z.; Shiv, H.P. Synthesis, structures second-harmonic generating, and ferroelectric properties of tungsten bronzes: $\mathrm{A}_{6} \mathrm{M}_{2} \mathrm{M}_{8}{ }_{8} \mathrm{O}_{30}\left(\mathrm{~A}=\mathrm{Sr}^{2+}, \mathrm{Ba}^{2+}\right.$, or $\mathrm{Pb}^{2+} ; \mathrm{M}=\mathrm{Ti}^{4+}, \mathrm{Zr}^{4+}$, or $\mathrm{Hf}^{4+}$; $\mathrm{M}^{\prime}=\mathrm{Nb}^{5+}$ or $\left.\mathrm{Ta}^{5+}\right)$. Chem. Mater. 2004, 16, 3616-3622.

81. Zheng, L.; Wang, J.; Huo, X.; Wang, R.; Sang, S.; Li, S.; Zheng, P.; Cao, W. Temperature dependence of dielectric and electromechanical properties of $(\mathrm{KNa})(\mathrm{NbTa}) \mathrm{O}_{3}$ single crystals and corresponding domain structure evolution. J. Appl. Phys. 2014, 116, 041105. [CrossRef] [PubMed]

82. Fu, X.; Víllora, E.G.; Matsushita, Y.; Kitanaka, Y.; Noguchi, Y.; Miyayama, M.; Shimamura, K.; Ohashi, N. Temperature dependence of electrical resistivity, dielectric and piezoelectric properties of $\mathrm{Ca}_{3} \mathrm{TaGa}_{3-\mathrm{x}} \mathrm{Al}_{\mathrm{x}} \mathrm{Si}_{2} \mathrm{O}_{14}$ single crystals as a function of $\mathrm{Al}$ content. J. Alloys Comp. 2016, 687, 797-803. [CrossRef]

83. Yu, F.; Lu, Q.; Zhang, S.; Wang, H.; Cheng, X.; Zhao, X. High-performance, high-temperature piezoelectric $\mathrm{BiB}_{3} \mathrm{O}_{6}$ crystals. J. Mater. Chem. 2015, C3, 329-338.

84. Belik, A.A.; Rusakov, D.A.; Furubayashi, T.; Takayama-Muromachi, E. $\mathrm{BiGaO}_{3}$-based perovskites: A large family of polar materials. Chem. Mater. 2012, 24, 3056-3064. [CrossRef]

85. Kaczkowski, J. Electronic structure, ferroelectric properties, and phase stability of $\mathrm{BiGaO}_{3}$ under high pressure from first principles. J. Mater. Sci. 2016, 51, 9761-9770. [CrossRef]

86. Kumar, A.; Rai, R.C.; Podraza, N.J.; Denev, S.R.; Chu, Y.-H.; Martin, L.W.; Ihlefeld, J.; Neeg, T.; Schubert, T.H.; Schlom, D.G.; et al. Linear and nonlinear properties of $\mathrm{BiFeO}_{3}$. Appl. Phys. Lett. 2008, 92, 121915. [CrossRef]

87. Ma, D.L.; Ren, M.-L.; Dou, J.-H.; Li, Z.Y. Giant Enhancement of second harmonic generation at photonic gap edges. Chin. Phys. Lett. 2010, 27, 114209.

88. Lottermoser, T.; Meier, D.; Pisarev, R.V.; Fiebig, M. Giant coupling of second-harmonic generation to a multiferroic polarization. Phys. Rev. 2009, B80, 100101. [CrossRef]

89. Heimann, R.B.; Hengst, M.; Rossberg, M. Giant optical rotation in piezoelectric crystals with calcium gallium germanate structure. Phys. Status Solidi. A Appl. Mater. Sci. 2003, 195, 468-474. 
90. Fan, Z.; Xiao, J.; Liu, H.; Yang, P.; Ke, Q.; Ji, W.; Yao, K.; Ong, K.P.; Zeng, K.; Wang, J. Stable ferroelectric perovskite structure with giant axial ratio and polarization in epitaxial BiFe0.6Ga0.4O3 thin films. ACS Appl. Mater. Interfaces 2015, 7, 2648-2653. [CrossRef] [PubMed]

91. Flach, S.; Gorbach, A. Discrete breathers: Advances in theory and applications. Phys. Rep. 2008, 467, 1-116. [CrossRef]

92. Yushkin, N.P. Mechanical Properties of Minerals; Nauka: Leningrad, Russia, 1971. (In Russian)

93. Marfunin, A.S. Introduction in Mineral Physics; Nedra: Moscow, Russia, 1974. (In Russian)

94. Feklichev, V.G. Diagnostic Constants of Minerals; Nedra: Moscow, Russia, 1989. (In Russian)

95. Marfunin, A.S. Advanced Mineralogy. In V.1. Composition, Structure and Properties of Mineral Matter; Concepts, Results, and Problems; Springer: Berlin, Germany, 1994; p. 550.

96. Okhotin, A.S.; Borovikova, R.P.; Nechaeva, T.V.; Pushkarskiii, A.S. Thermal Conductivity of Solid State; Energo-atomizdat: Moscow, Russia, 1984. (In Russian)

97. Samsonov, G.V.; Bulankova, T.G.; Burykina, A.L. Physical and Chemical Properties of Oxides; Metallurghiya: Moscow, Russia, 1969. (In Russian)

98. Bohaty, L.; Haussuhl, S.; Liebertz, J.; Stahr, S. Single crystal growth and physical property of cubic $\mathrm{Zn} 4 \mathrm{O}\left(\mathrm{BO}_{2}\right)_{3}$. Z. Krist. 1982, 164, 157-158. [CrossRef]

99. Gubina, Yu.K.; Belokoneva, E.L. The electronic density and chemical bond in the ultramarine crystals. Rep. Acad. Sci. 2001, 376, 662-666. (In Russian)

100. Jiang, X.; Molokeev, M.S.; Gong, P.; Wang, W.; Wang, S.; Wu, S.; Wang, Y.; Huang, R.; Li, R.; Wu, Y.; et al. Near zero thermal expansion and high ultraviolet transparency in borate crystal of $\mathrm{Zn}_{4} \mathrm{~B}_{6} \mathrm{O}_{13}$. Adv. Mater. 2016, 28, 7936-7940. [CrossRef] [PubMed]

101. Korotkov, A.S. Correlation of optical properties of acentric crystals with chemical composition. Opt. Commun. 2013, 294, 218-222. [CrossRef]

102. Hautier, G.; Fisher, C.C.; Jain, A.; Mueller, T.; Ceder, G. Finding nature's missing ternary oxide compounds using machine learning and density functional theory. Chem. Mater. 2010, 22, 3762-3767. [CrossRef]

103. Song, J.L.; Hu, C.-L.; Xu, X. A facile synthetic route to a new SHG material with two types of parallel pi-conjugated planar triangular units. Angew. Chem. Int. Ed. 2015, 54, 3679-3682. [CrossRef] [PubMed]

104. Ye, N. Structure design and crystal growth of UV nonlinear borate. Mater. Struct. Bond. 2012, 144, $181-222$.

105. Belokoneva, E.L.; Stefanovich, S.Y.; Borisova, T.A.; Dimitrova, O.V.; Vochenova, N.N.; Zubkova, N.V. Structure and nonlinear optical properties of the family of lead and barium nonaborates with zeolite-like framework. Crystallogr. Rep. 2009, 54, 814-821. [CrossRef]

106. Abudoureheman, M.; Wang, L.; Zhang, X.; Yu, H.; Yang, Z.; Lei, C.; Han, J.; Pan, S. Pb $7 \mathrm{O}(\mathrm{OH})_{3}\left(\mathrm{BO}_{3}\right) \mathrm{CO}_{3}$ : First mixed borate and carbonate nonlinear optical material exhibiting large second harmonic generation response. Inorg. Chem. 2015, 54, 4138-4142. [CrossRef] [PubMed]

107. Wei, Q.; Cheng, J.-W.; He, C.; Yang, G.-Y. An acentric calcium borate $\mathrm{Ca}_{2}\left[\mathrm{~B}_{5} \mathrm{O}_{9}\right] \cdot(\mathrm{OH}) \cdot \mathrm{H}_{2} \mathrm{O}$. Synthesis, structure, and nonliner optical property. Inorg. Chem. 2014, 53, 11757-11763. [CrossRef] [PubMed]

108. Wang, L.; Pan, S.; Chang, L.; Hu, J.; Yu, Y. UV nonlinear optical crystal $\mathrm{Ba}^{-2}\left[\mathrm{~B}_{6} \mathrm{O}_{9}(\mathrm{OH})_{4}\right]$.Featuring unique chiral layers with a new $\mathrm{B}_{18} \mathrm{O}_{42}$ circle based on $\mathrm{BO}_{3}$ and $\mathrm{BO}_{4}$ units. Inorg. Chem. 2012, 51, 1852-1858. [CrossRef] [PubMed]

109. Yang, H.; Hu, C.-L.; Xu, X.; Mao, J.-G. Series of SHG Materials Based on Lanthanide Borate-Acetate Mixed Anion Compounds. Inorg. Chem. 2015, 54, 7516-7523. [CrossRef] [PubMed]

110. Barbier, J.; Cranswick, L.M.D. The non-centrosymmetric borate oxides, $\mathrm{MBi}_{2} \mathrm{~B}_{2} \mathrm{O}_{7}(\mathrm{M}=\mathrm{Ca}$, Sr). J. Solid State Chem. 2006, 179, 3932-3938. [CrossRef]

111. Zhang, F.; Qun, J.; Zhang, F.; Pan, S.; Yang, Z.; Yan, J.; Yan, $\mathrm{S}$. $\mathrm{Sr}_{4} \mathrm{~B}_{10} \mathrm{O}_{18}(\mathrm{OH})_{2}$ center dot $2 \mathrm{H}_{2} \mathrm{O}$ : A new UV nonlinear optical material with a $\left[\mathrm{B}_{10} \mathrm{O}_{23}\right]_{16}$ building block. J. Mater. C 2013, 23, 667-674. [CrossRef]

112. Belokoneva, E.L.; Topnikova, A.P.; Stefanovich, S.Yu; Dobretsova, E.A.; Volkov, A.S.; Dimitrova, O.V. New isoformula borates with similar structures and different properties-Acentric nonlinear optical $\mathrm{KGd}\left[\mathrm{B}_{6} \mathrm{O}_{10}(\mathrm{OH})_{2}\right]$ and centrosymmetric $\mathrm{KHo}\left[\mathrm{B}_{6} \mathrm{O}_{10}(\mathrm{OH})_{2}\right]$. Solid State Sci. 2015, 46, 43-48. [CrossRef]

113. Dong, L.; Pan, S.; Wang, Y. Synthesis and structural characterization of a new rubidium borosulfate, $\mathrm{Rb}_{5} \mathrm{BS}_{4} \mathrm{O}_{16}$. Mater. Res. Bull. 2015, 63, 93-98. [CrossRef]

114. Becker, P. A contribution to borate crystal chemistry: Rules for the occurrence of polyborate anion types. Z. Crystallogr. 2001, 216, 523-533. [CrossRef]

115. Frölich, R. Crystal structure of the low temperature form of $\mathrm{BaB}_{2} \mathrm{O}_{4}$. Z. Krist. 1984, 168, 109-112. [CrossRef] 
116. Chen, C.; Wu, B.; Jiang, A.; You, G. A new type ultraviolet SHG crystal BaB $\mathrm{O}_{4}$. Sci. Sinica 1985, B38, $235-243$.

117. Jiang, A.; Cheng, F.; Lin, Q.; Cheng, G.; Zheng, Y. Flux growth of large single crystals of low temperature phase of barium metaborate. J. Cryst. Growth 1986, 79, 963-969.

118. Ito, K.; Marumo, F.; Kuvano, Y. $\beta$-baium borate single crystal growth by a direct Czochralski method. J. Cryst. Growth 1990, 106, 728-731. [CrossRef]

119. Kokh, A.E.; Bekker, T.B.; Vlezko, V.A.; Kokh, K.A. Development of $\beta-\mathrm{BaB}_{2} \mathrm{O}_{4}$ crystal growth technique in the heald field of thrre fold axis symmetry. J. Cryst. Growth 2011, 318, 602-605. [CrossRef]

120. Wang, X.; Yan, X.; Luo, S.; Chen, C.T. Flux growth of $\mathrm{KBe}_{2} \mathrm{BO}_{3} \mathrm{~F}_{2}$ crystals by localized spontaneous nucleation. J. Cryst. Growth 1995, 318, 610-612. [CrossRef]

121. Mei, L.F.; Huang, X.; Wang, Y.B.; Wu, B.C.; Chen, C.T. Crystal structure of $\mathrm{KBe}_{2} \mathrm{BO}_{3} \mathrm{~F}_{2}$. Z. Krist. New Cryst. Struct. 1995, 210, 93-95. [CrossRef]

122. Wu, B.; Tang, D.; Ye, N.; Chen, C.T. Linear and nonlinear optical properties of the $\mathrm{KBe}_{2} \mathrm{BO}_{3} \mathrm{~F}_{2}(\mathrm{KBBF})$ crystal. Opt. Mater. 1996, 5, 105-109. [CrossRef]

123. Chen, C.T.; Wang, E.; Wu, B.; Wu, K.; Zeng, W.; Yu, L. Design and synthesis of an ultraviolet-transparent nonlinear optical crystal $\mathrm{Sr}_{2} \mathrm{Be}_{2} \mathrm{~B}_{2} \mathrm{O}_{7}$ (SBBO). Nature 1995, 373, 322-324. [CrossRef]

124. Hu, Z.G.; Yoshimura, M.; Muramatsu, K.; Mori, Y.; Sasaki, T. A new nonlinear optical crystals $\mathrm{BaAlBO}_{3} \mathrm{~F}_{2}$ (BABF). Jpn. J. Appl. Phys. 2002, 41, L1131-L1133. [CrossRef]

125. Yeliseyev, A.P.; Solntsev, V.P.; Jiang, X.; Bekker, T.B.; Lin, Z.; Fedorov, P.P. Electronic structure, magnetic and optical properties of the $\mathrm{Ba}_{7}\left(\mathrm{BO}_{3}\right) 4-\mathrm{xF}_{2+3 x}$ crystals. J. Solid State Chem. 2015, 229, 358-365. [CrossRef]

126. Chen, C.T.; Luo, S.Y.; Wang, X.Y.; Wen, X.H.; Wu, H.X.; Zhang, X.; Xu, Z.Y. Deep UV nonlinear optical crystal $\mathrm{RbBe}_{2} \mathrm{BO}_{3} \mathrm{~F}_{2}$ (KBBF). J. Opt. Soc. Am. B 2009, 26, 1519-1525. [CrossRef]

127. Wang, Y.; Pan, S. Recent development of metal borate halides: Crystal chemistry and application in second order NLO materials. Coord. Chem. Rev. 2016, 323, 15-35. [CrossRef]

128. Yu, N.; Wang, S.; Ye, N.; Liang, F.; Lin, Z.; Luo, M.; Poeppelmeier, K.R. A deep ultra-violet nonlinear optical crystal: Strontium beryllium borate fluoride with planar Be(O/F) 3 groups. Chem. Mater. 2016, 28, 4563-4571. [CrossRef]

129. Bian, Q.; Yang, Z.; Wang, Y.; Cao, C.; Pan, S. Predicting global minimum in complex beryllium borate system for deep-ultraviolet functional optical application. Sci. Rep. 2016, 6, 34839. [CrossRef] [PubMed]

130. Bashir, D.; Zhang, B.; Lei, B.-H.; Yang, Z.; Lee, M.-H.; Pan, S. DFT based theoretical study about the contribution of fluorine to nonlinear optical properties in borate fluoride crystals. Cryst. Growth Des. 2016, 16, 5067-5073. [CrossRef]

131. Lin, Y.; $\mathrm{Hu}$, C.-L.; Mao, J.-G. $\mathrm{K}_{2} \mathrm{~Pb}_{3}\left(\mathrm{CO}_{3}\right)_{3} \mathrm{~F}_{2}$ and $\mathrm{KCdCO}_{3} \mathrm{~F}$ : Novel Fluoride Carbonates with Layered and 3D Framework Structures. Inorg. Chem. 2015, 54, 10407-10414. [CrossRef] [PubMed]

132. Luo, M.; Lin, C.; Zou, G.; Ye, N.; Cheng, W. Sodium rare earth carbonates with shorite structure and large second harmonic generation response. CrystEngComm 2014, 16, 4414-4421. [CrossRef]

133. Yeung, H.H.-M.; Kosa, M.; Parrinello, M.; Cheetham, A.K. Chiral, racemic, and meso-lithium tartrate framework polymorphs: A detailed structural analysis. Cryst. Growth Des. 2013, 13, 3705-3715. [CrossRef]

134. Weil, M. Crystal structure of lead(II) tartrate: A redetermination. Acta Crystallogr. Sect. E Crystallogr. Commun. 2015, E71, 82-89. [CrossRef] [PubMed]

135. Cortese, A.J.; Wilkins, B.; Smith, M.D. Crystal Growth of Four Oxovanadium (IV) Tartrates Prepared via a Mild Two-Step Hydrothermal method: Observation of Spin-Dimer Behavior and Second Harmonic generation. Inorg. Chem. 2015, 54, 4011-4020. [CrossRef] [PubMed]

136. Gomez-Aguirre, L.C.; Pato-Doldan, B.; Stroppa, A.; Yaňez-Vilar, S.; Bayarjargal, L.; Winkler, B.; Castro-García, S.; Mira, J.; Sánchez-Anújar, M.; Señarís-Rodríguez, M.A. Room-temperature polar order in $\left[\mathrm{NH}_{4}\right]\left[\mathrm{Cd}(\mathrm{HCOO})_{3}\right]$-a hybrid inorganic-organic compound with a unique perovskite architecture. Inorg. Chem. 2015, 54, 2109-2116. [CrossRef] [PubMed]

137. Essid, M.; Rzaigui, M.; Marouani, H. Synthesis and physico-chemical studies of a new noncentrosymmetric Bis[N-(2-hydroxyethyl)piperazine-1,4-tetrakis(hydrogen oxalate) trihydrate; diium] $\left[\mathrm{C}_{6} \mathrm{H}_{16} \mathrm{~N}_{2} \mathrm{O}_{2}\left(\mathrm{HC}_{2} \mathrm{O}_{4}\right)_{4}\right.$ $\mathrm{H}_{2} \mathrm{O}\left[\mathrm{C}_{6} \mathrm{H}_{6}{ }_{6} \mathrm{~N} 2 \mathrm{O}\right]_{2}\left(\mathrm{HC}_{2} \mathrm{O} 4\right)_{4} . \mathrm{H}_{2} \mathrm{O}$. Inorg. Chem. 2015, 54, 2109-2116.

138. Norby, P.; Dinnebier, R.; Fitch, A.N. Decomposition of silver carbonate; the crystal structure of two high-temperature modifications of $\mathrm{Ag}_{2} \mathrm{CO}_{3}$. Inorg. Chem. 2002, 41, 3628-3637. [CrossRef] [PubMed]

139. Hu, J.; Ma, Z.; Sa, R.; Zhang, Y.; Wu, K. A promising lead-free fluoride carbonate SHG material designed from a theoretical perspective. Dalton Trans. 2017, 46, 2635-2642. [CrossRef] [PubMed] 
140. Krivovichev, S.V.; Burns, P.C. Crystal chemistry of basic lead carbonates. II. Crystal structure of synthetic 'plumbonacrite'. Mineral. Mag. 2000, 64, 1069-1075. [CrossRef]

141. Hassan, I.; Buse, P.R. The origin of the superstructure and modulation in cancrinite. Can. Mineral. 1992, 30, $49-59$.

142. Schmidbaur, H.; Kumberger, O. Preparative, X-ray, and NMR studies of the interaction of beryllium with salicylic and o-cresotic acid: Crystal structures of $\left(\mathrm{NH}_{4}\right)_{2}\left[\mathrm{Be}\left(\mathrm{C}_{6} \mathrm{H}_{4} \mathrm{OCO}_{2}\right)_{2}\right] 2.25 \mathrm{H}_{2} \mathrm{O}$ and $\mathrm{Na}_{3}\left[\mathrm{Be}\left(\mathrm{C}_{7} \mathrm{H}_{6} \mathrm{OCO}_{2}\right)(\mathrm{OH})\left(\mathrm{CO}_{3}\right) \mathrm{Be}\left(\mathrm{C}_{7} \mathrm{H}_{6} \mathrm{OCO}_{2}\right)\right] \cdot 8 \mathrm{H}_{2} \mathrm{O}$. Chem. Ber. 1993, 126, 3-9. [CrossRef]

143. Greaves, C.; Blower, S.K. Structural relationships between $\mathrm{Bi}_{2} \mathrm{O}_{2} \mathrm{CO}_{3}$ and $\beta-\mathrm{Bi}_{2} \mathrm{O}_{3}$. Mater. Res. Bull. 1988, 23, 1001-1008. [CrossRef]

144. Kutlu, I.; Kalz, H.J.; Wartchow, R. Potassium lanthanoid carbonates, $\left.\mathrm{KM}\left(\mathrm{CO}_{3}\right)_{2}\right)(\mathrm{M}=\mathrm{Nd}, \mathrm{Gd}, \mathrm{Dy}, \mathrm{Ho} \mathrm{Yb})$. Z. Anorg. Allg. Chem. 1997, 623, 1753-1758. [CrossRef]

145. Labutina, M.L.; Marychev, M.O.; Portnov, V.N.; Somov, N.V.; Chuprunov, E.V. Second_Order Nonlinear Susceptibilities of the Crystals of Some Metal Tartrates. Crystallogr. Rep. 2011, 56, 72-74. (In Russian) [CrossRef]

146. Zhang, G.; Liu, T.; Zhu, T.; Qin, J.; Wu, Y.; Chen, C. SbF 3 : A new second-order nonlinear optical material. Opt. Mater. 2008, 31, 110-113. [CrossRef]

147. Wright, A.C. My borate life: An enigmatic journey. Int. J. Appl. Glass Sci. 2015, 145, 45-63. [CrossRef]

148. Bengisu, M. Borate glasses for scientific and industrial application: A review. J. Mater. Sci. 2016, 51, $2199-2242$. [CrossRef]

149. Taziev, R.M. SAW excitation properties on YX-cut of CNGS and SNGS single crystals. IEEE Trans. Ultrason. Ferroelect. Freq. Control 2010, 57, 2370-2371. [CrossRef] [PubMed]

150. Gazhulina, A.P.; Marychev, M.O. Pseudosymmetric features and nonlinear optical properties of potassium titanyl phosphate crystals. Cryst. Struct. Theory Appl. 2013, 2, 109-119. [CrossRef]

151. Gazhulina, A.P.; Marychev, M.O. Structural electronic and nonlinear optical properties of B3 and B20 compounds: A first principles investigation within the LDA, GGA, and modified Becke Johnson exchange potential plus LDA. J. Alloy Comp. 2015, 623, 413-437. [CrossRef]

152. Gazhulina, A.P.; Marychev, M.O. Pseudosymmetric features of non-centrosymmetric AB type crystals. J. Solid State Chem. 2016, 239, 170-177. [CrossRef]

153. Arkhipov, S.G.; Boldyreva, E.V. Algorithm of existence detection and reproducible receiving of the single salt crystals and mixed crystals of amino acids, useful to roentgen-structure and CR-spectroscopy experimental studies. J. Struct. Chem. 2014, 55, 778-783. [CrossRef]

154. Konstantinova, A.F.; Golovina, T.G.; Konstantinov, K.K. The manifestation of the optical activity in different substances. Crystallography 2014, 59, 509-528.

155. Shvartsev, S.L. How the complexities are formed. Vestnik RAN 2014, 84, 618-628. 